\title{
Extensive protein expression changes induced by pamidronate in RAW 264.7 cells as determined by IP-HPLC
}

\author{
Sang Shin Lee ${ }^{1}$, Soung Min Kim ${ }^{2}$, Yeon Sook Kim ${ }^{3}$, Suk Keun Lee ${ }^{\text {Corresp. } 1}$ \\ ${ }^{1}$ Department of Oral Pathology, College of Dentistry, Gangneung-Wonju National University, Gangneung, Gangwondo, South Korea \\ 2 Department of Oral and Maxillofacial Surgery, College of Dentistry, Seoul National University, Seoul, South Korea \\ 3 Department of Dental Hygiene, College of Health \& Medical Sciences, Cheongju University, Cheongju, South Korea \\ Corresponding Author: Suk Keun Lee \\ Email address: sklee@gwnu.ac.kr
}

Background. Bisphosphonate therapy has become a popular treatment for osteoporosis, Paget's disease, multiple myeloma, osteogenesis imperfecta, myocardial infarction, and cancer despite its serious side effects. Bisphosphonate-induced molecular signaling changes in cells are still not clearly elucidated. Methods. As bisphosphonates are primarily engulfed by macrophages, we treated RAW 264.7 cells (a murine macrophage cell line) with pamidronate and investigated global protein expressional changes in cells by immunoprecipitation high performance liquid chromatography (IP-HPLC) using 218 antisera. Results. Pamidronate upregulated proliferation-activating proteins associated with $\mathrm{p} 53 / \mathrm{Rb} / \mathrm{E} 2 \mathrm{~F}$ and $\mathrm{Wnt} / \mathrm{\beta}$-catenin pathways, but downregulated the downstream of RAS signaling, pAKT1/2/3, ERK-1, and p-ERK-1, and subsequently suppressed cMyc/MAX/MAD network. However, in situ proliferation index of pamidronate-treated RAW264.7 cells was slightly increased by $3.2 \%$ versus non-treated controls. Pamidronate-treated cells showed increase in the expressions of histone- and DNA methylation-related proteinsbut decrease of protein translation-related proteins. NFkB signaling was also suppressed as indicated by the down-regulations of p38 and p-p38 and the up-regulation of $\mathrm{mTOR}$, while the protein expressions related to cellular protection, HSP-70, NRF2, JNK-1, and LC3 were upregulated. Consequently, pamidronate downregulated the protein expressions related to immediate inflammation,cellular differentiation, survival, angiogenesis, and osteoclastogenesis, but upregulated PARP-1 and FAS-mediated apoptosis proteins. These observations suggest pamidronate affects global protein expressions in RAW 264.7 cells by stimulating cellular proliferation, protection, and apoptosis but suppressing immediate inflammation, differentiation, osteoclastogenesis, and angiogenesis. Accordingly, pamidronate appears to affect macrophages in several ways eliciting not only itstherapeutic effects but also atypical epigenetic modification, protein translation, RAS and NFkB signalings. Therefore, our observations suggest pamidronate-induced protein expressions are dynamic, and the 
affected proteins should be monitored by IP-HPLC to achieve the therapeutic goals during treatment. 


\section{Extensive protein expression changes induced by pamidronate in RAW 264.7 cells as determined by IP- HPLC \\ ${ }^{1}$ Department of Oral Pathology, College of Dentistry, Gangneung-Wonju National University, Gangneung; Korea \\ ${ }^{2}$ Department of Oral and Maxillofacial Surgery, College of Dentistry, Seoul National University, Seoul; Korea \\ ${ }^{3}$ Department of Dental Hygiene, College of Health \& Medical Sciences, Cheongju University, Cheongju; Korea}

3

4

5

6

7

8

9 10

Short title: Pamidronate-induced protein expressions

Corresponding Author:

Suk Keun Lee, DDS, MSD, PhD.

Department of Oral Pathology, College of Dentistry, Gangneung-Wonju National University, 123 Chibyundong, Gangneung, 210-702, Korea

E-mail : sklee@gwnu.ac.kr 
28

29

30

31

32

33

34

35

36

37

38

39

40

41

42

43

44

45

46

47

48

49

50

51

\section{Abstract}

\section{Background.}

Bisphosphonate therapy has become a popular treatment for osteoporosis, Paget's disease, multiple myeloma, osteogenesis imperfecta, myocardial infarction, and cancer despite its serious side effects. Bisphosphonate-induced molecular signaling changes in cells are still not clearly elucidated.

\section{Methods.}

As bisphosphonates are primarily engulfed by macrophages, we treated RAW 264.7 cells (a murine macrophage cell line) with pamidronate and investigated global protein expressional changes in cells by immunoprecipitation high performance liquid chromatography (IP-HPLC) using 218 antisera.

\section{Results.}

Pamidronate upregulated proliferation-activating proteins associated with $\mathrm{p} 53 / \mathrm{Rb} / \mathrm{E} 2 \mathrm{~F}$ and Wnt/ß-catenin pathways, but downregulated the downstream of RAS signaling, pAKT1/2/3, ERK-1, and p-ERK-1, and subsequently suppressed cMyc/MAX/MAD network. However, in situ proliferation index of pamidronate-treated RAW264.7 cells was slightly increased by $3.2 \%$ versus non-treated controls. Pamidronate-treated cells showed increase in the expressions of histone- and DNA methylation-related proteins but decrease of protein translation-related proteins. NFkB signaling was also suppressed as indicated by the down-regulations of p38 and p-p38 and the upregulation of mTOR, while the protein expressions related to cellular protection, HSP70, NRF2, JNK-1, and LC3 were upregulated. Consequently, pamidronate downregulated the protein expressions related to immediate inflammation, cellular 
52 differentiation, survival, angiogenesis, and osteoclastogenesis, but upregulated PARP-1

53 and FAS-mediated apoptosis proteins. These observations suggest pamidronate affects

54 global protein expressions in RAW 264.7 cells by stimulating cellular proliferation,

55 protection, and apoptosis but suppressing immediate inflammation, differentiation,

osteoclastogenesis, and angiogenesis. Accordingly, pamidronate appears to affect

57 macrophages in several ways eliciting not only its therapeutic effects but also atypical

58 epigenetic modification, protein translation, RAS and NFkB signalings. Therefore, our observations suggest pamidronate-induced protein expressions are dynamic, and the

60 affected proteins should be monitored by IP-HPLC to achieve the therapeutic goals 61 during treatment.

64

65 66

67

\section{Introduction}

Bone undergoes constant remodeling maintained by a balance between osteoblasts and osteoclasts. Bisphosphonates inhibit the digestion of bone by causing osteoclasts to undergo apoptosis (Ito et al. 2001) and impair osteoclasts' ability to form a ruffled border (Sato et al. 1991), to adhere to the bone surface, and to synthesize protons necessary for bone resorption. Furthermore, bisphosphonates suppress osteoclast activity by decreasing osteoclast progenitor development and recruitment (Cecchini et al. 1987; Endo et al. 1993). These diphosphate analogs inhibit intermediate enzymes of mevalonate pathway and are used to treat osteoporosis and Paget's disease (historically osteitis deformans) (Abelson 2008). In osteoporosis and Paget's disease, IV zoledronic acid is the first-choice treatment for Paget disease because of its efficacy 
76

77

78

79

80

81

82

83

84

85

86

87

88

89

90

91

92

93

94

95

96

97

98

and ease of administration (Wat 2014). The choice of zoledronic acid as the initial agent for most patients with active Paget disease is consistent with both the 2014 clinical practice guidelines of the Endocrine Society and the 2019 Paget's Association guidelines (Singer et al. 2014).

Bisphosphonates bind calcium and are readily deposited in bone. They also change bone ultrastructures, e.g., they obliterate Haversian canals and deposit irregular and thick reversal lines (Acevedo et al. 2015; Carmagnola et al. 2013; Kim et al. 2017c; Lee 2013). The common side effects of bisphosphonates include bone pain, low blood calcium levels, nausea, and dizziness. In addition, bisphosphonate-related osteonecrosis of the jaw (BRONJ) may develop in patients who have used bisphosphonates long term (Marx et al. 2005; Ruggiero et al. 2004). Total 37 BRONJ cases out of 1014 patients using bisphosphonates for osteoporosis treatment showed $62.6 \%$ were associated with intravenous and $37.4 \%$ with oral application (Hansen et al. 2012). The incidence of BRONJ is known to be low among patients treated with oral bisphosphonates (Sarasquete et al. 2009). The estimated prevalence of oral BRONJ was $0.05-0.07 \%$. And the average oral bisphosphonate treatment duration was 43.1 months (range, 5-120 months) (Hong et al. 2010). Among the 320 osteoporotic patients who underwent tooth extraction, 11 developed BRONJ, reflecting an incidence rate of $3.44 \%$. And the incidence of BRONJ increased with age, was greater in the mandible than the maxilla, and was associated with a duration of administration of more than 3 years (Jeong et al. 2017; Marx et al. 2005; Ruggiero et al. 2004). The pathophysiology of BRONJ is currently unclear. BRONJ has been attributed to infection (Chirappapha et al. 2017; Choi et al. 2017; Park et al. 2009), bisphosphonate-related osteonecrosis 
99 (Guimaraes et al. 2013), quantitative reduction of the vascularization (Kun-Darbois et al. 100 2018), local immune dysfunction (Hoefert et al. 2016b), genetic predisposition like 101 polymorphisms on CYP2C8 gene (Sarasquete et al. 2009), etc.

102 In addition, to the anti-osteoporotic effect of bisphosphonates, adjunctive 103 bisphosphonate therapy appears to be effective at managing periodontitis (Akram et al. 104 2017), fibrous dysplasia (Majoor et al. 2017), and Gorham-Stout disease (Hammer et al. 105 2005; Kim et al. 2015). Therefore, it is believed bisphosphonates may have several 106 systemic effects such as anti-inflammatory, anti-proliferative, and anti-angiogenesis 107 effects (Kamel et al. 2012; Ohlrich et al. 2016; Ribatti et al. 2008). However, the 108 biological effects of bisphosphonates in different cells have not been clearly elucidated 109 at the molecular level.

110 Pamidronate (pamidronate disodium or pamidronate disodium pentahydrate) is a 111 nitrogen-containing bisphosphonate and used to prevent bone loss due to steroid use

112 like glucocorticoid-induced low bone mineral density in children (Jayasena et al. 2015)

113 or to inhibit calcium release from bone by impairing osteoclast-mediated bone 114 resorption (Miyazaki et al. 2011), pamidronate is frequently used to treat high calcium

115 levels (Polyzos et al. 2011). In addition, it has also been used as an experimental 116 treatment for osteogenesis imperfecta and been studied for the treatment of complex 117 regional pain syndrome (Chevreau et al. 2017).

118 Immunoprecipitation high-performance liquid chromatography (IP-HPLC) had been 119 used previously by several authors to detect organic compounds including peptides 120 quantitatively, but the technique used was complicated and of limited applicability 121 (Clarke et al. 1998; Luo et al. 2013). Recently, a new IP-HPLC protocol was developed 
122 to determine protein expression levels in different biological fluids, such as blood serum,

123 urine, saliva (Kim \& Lee 2015), inflammatory exudates (Kim et al. 2017a; b; 2018), and

124 different protein extracts from cells (Kim et al. 2019; Yoon et al. 2018b), liver (Yoon et

125 al. 2018a), and cancer tissues (Kim et al. 2017d). The IP-HPLC is comparable to

126 enzyme-linked immunosorbent assay (ELISA). The former uses protein A/G agarose

127 beads in buffer solution and UV spectroscopy to determine protein concentrations,

128 whereas the latter uses fluorescence-conjugated antibodies fixed in plastic wells and

129 fluoroscopy. Furthermore, multiple trials have shown that IP-HPLC can be used to 130 rapidly determine multiple protein levels accurately (< $<5 \%$ standard deviation) and

131 reproducibly. In the previous study (Yoon et al. 2018b), 64 proteins were assessed by

132 IP-HPLC 4-8 times repeatedly and their results showed low error range $< \pm 5 \%$ standard 133 deviation (shown in the raw data sheets of supplementary dataset 5).

134 When pamidronate is injected into blood vessels, it immediately chelates $\mathrm{Ca}^{++}$ 135 (Ebetino et al. 2011; Fernandez et al. 2002) and is bound to serum albumin (90\% of 136 tiludronate) (Sansom et al. 1995), and subsequently recognized by macrophages, which 137 suggests its various pharmacologic effects may be associated with the cellular functions 138 of pamidronate-laden macrophages. Therefore, the present in vitro study was 139 undertaken to investigate the effects of pamidronate on protein expressions in RAW 140264.7 macrophages by IP-HPLC.

Materials \& Methods

144

RAW264.7 cell culture with pamidronate treatment 
RAW 264.7 cells, an immortalized murine macrophage cell line (ATCC, USA), were

147 cultured as previously described (Yoon et al. 2018b). About 70\% confluent RAW 264.7

148 cells grown on Petri dish surfaces were treated with $6.5 \mu \mathrm{M}$ disodium pamidronate

149 (similar to the therapeutic dose, $1.5 \mathrm{mg} / \mathrm{kg}$ ) (Sigma, USA) for 12, 24, or $48 \mathrm{~h}$; control

150 cells were treated with $1 \mathrm{~mL}$ of normal saline. Cultured cells were harvested with protein

151 lysis buffer (PRO-PREPTM, iNtRON Biotechnology INC, Korea) and immediately

152 preserved at $-70^{\circ} \mathrm{C}$ until required.

153

In situ proliferation index of RAW 264.7 cells after 24 h of pamidronate treatment

RAW 264.7 cell proliferations were directly observed on plastic surfaces of Petri

dishes after treatment with pamidronate at $6.5 \mu \mathrm{M}$ for 12,24 , or $48 \mathrm{~h}$, and compared

with non-treated controls. When cells formed clusters containing $20-30$ cells after $24 \mathrm{~h}$

of pamidronate treatment, ten representative histological images (taken at areas

159

photographed before pamidronate treatment) were obtained using an inverted

microscope (DP-73, Olympus Co., Japan). Cell numbers were obtained using the

iSolution Lite program (IMT i-Solution Inc., Canada), proliferation indices were

calculated by dividing increases in cell numbers after $24 \mathrm{~h}$ and $48 \mathrm{~h}$ of culture by initial

cell numbers and compared between pamidronate treatment groups and non-treated

controls.

165

Immunoprecipitation high-performance liquid chromatography (IP-HPLC)

Protein extracts (about 100 $\mu \mathrm{g}$ ) were subjected to immunoprecipitation using a

protein A/G agarose column (Amicogen, Korea). Protein A/G agarose columns were 
169

170

171

172

173

174

175

176

177

178

179

180

181

182

183

184

185

186

187

188

189

190

191

separately pre-incubated with $1 \mu \mathrm{g}$ of 218 different antisera (147 monoclonal antibodies and 71 polyclonal antibodies (36 antibodies were purified with affinity columns) specific to target amino acid motifs (product companies were listed in Table 1); for proliferationrelated proteins $(n=11)$, cMyc/MAX/MAD signaling proteins $(n=3(1)), p 53 / R b / E 2 F$ signaling proteins $(n=4(2)), W n t / \beta$-catenin signaling proteins $(n=6)$, epigenetic modification-related proteins $(n=7)$, protein translation-related proteins $(n=5)$, growth factor-related proteins $(n=18)$, RAS signaling proteins $(n=22)$, NFkB signaling proteins $(n=12(6))$, up-regulated inflammatory proteins $(n=17)$, down-regulated inflammatory proteins $(n=27(1))$, p53-mediated apoptosis-related proteins $(n=15(2))$, FAS-mediated apoptosis-related proteins $(n=5(3))$, cell survival-related proteins $(n=5(11)$, protectionrelated proteins $(n=12(13))$, differentiation-related proteins $(n=11(11))$, oncogenesisrelated proteins $(n=10(10))$, angiogenesis-related proteins $(n=14(9))$, osteogenesisrelated proteins $(n=11(4))$, and control housekeeping proteins $(n=3)$ (numbers in parenthesis indicate number of overlapping antibodies, Table 1).

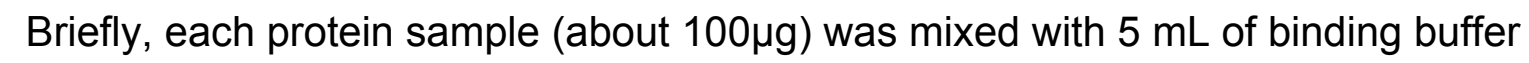
(150mM NaCl, 10mM Tris pH 7.4, 1mM EDTA, 1mM EGTA, 0.2mM sodium vanadate, 0.2mM PMSF, $0.5 \%$ NP-40, and mixture of protein inhibitors (Sigma, USA)) and incubated with protein A/G agarose beads (200 $\mu \mathrm{L}$, Amicogen, Korea) bound with objective antibody on a rotating stirrer for 1 hour at $4^{\circ} \mathrm{C}$. After washing beads with PBS (phosphate buffered saline solution), target proteins were eluted using $150 \mu \mathrm{L}$ of $\lg \mathrm{G}$ elution buffer (Pierce, USA). Immunoprecipitated proteins were analyzed using a HPLC unit (1100 series, Agilent, USA) equipped with a reverse phase column and a microanalytical detector system (SG Highteco, Korea), using 0.15M NaCl/20\% acetonitrile 
192 solution at $0.4 \mathrm{~mL} / \mathrm{min}$ for $30 \mathrm{~min}$, and proteins were detected using a UV spectrometer

193 at $280 \mathrm{~nm}$. Control and experimental samples were run sequentially to allow

194 comparisons. For IP-HPLC, whole protein peak areas (mAU*s) were mathematically

195 calculated with analytical algorithm (see Supplementary data 1) by subtracting negative

196 control antibody peak areas, and protein expression levels (mAU) were compared and

197 normalized using the square roots of protein peak areas. Analyses were repeated two to

198 six times to achieve mean standard deviations of $\leq \pm 5 \%$ (RAW data, Supplementary

199 data 2). Objective protein expression level (\%) between experiment and control groups

200 were calculated and results were analyzed using the chi-squared test program (Kim et

201 al. 2019; Yoon et al. 2018a; b).

202 The housekeeping proteins $\beta$-actin, $\alpha$-tubulin, and glyceraldehyde 3-phosphate 203 dehydrogenase (GAPDH) were also used as internal controls. Expressional changes of 204 housekeeping proteins were adjusted to $< \pm 5 \%$ using a proportional basal line 205 algorithm. Protein expressional changes of $\leq \pm 5 \%, \pm 5-10 \%, \pm 10-20 \%$, and $\geq \pm 20 \%$ 206 change were defined as minimal, slight, meaningful, or marked, respectively.

207 When the IP-HPLC results were compared with the western blot data of cytoplasmic 208 housekeeping protein ( $\beta$-actin), the former exhibiting minute error ranges less than $\pm 5 \%$ 209 and could be analyzed statistically, while the latter showed a large error range of more 210 than $20 \%$, and thus it was almost impossible to analyze them statistically (see

211 Supplementary data 3). Therefore, the present study utilized IP-HPLC to statically 212 analyze global protein expression changes in pamidronate-treated RAW 264.7 cells 213 rather than Western blot method (Seo et al. 2019). 


\section{Statistical analysis}

216 Proportional data (\%) of experimental and control groups were plotted, and

217 analyses were repeated two to six times until standard deviations were $\leq \pm 5 \%$. Results

218 were analyzed by measuring standard error $\left(s= \pm \sqrt{\frac{\sigma^{2}}{n}}\right)$. The expressions of control

219 housekeeping proteins, that is, $\beta$-actin, $\alpha$-tubulin, and glyceraldehyde 3 -phosphate 220 dehydrogenase (GAPDH) non-responsive $(\leq 5 \%)$ to 12,24 , or $48 \mathrm{~h}$ of pamidronate 221 treatment.

222

223

224

225

226

\section{Results}

In situ proliferation index of RAW 264.7 cells after 24 h of pamidronate treatment

Both $6.5 \mu \mathrm{M}$ pamidronate-treated RAW 264.7 cells and non-treated controls 228

proliferated on Petri dishes and formed large cell clusters after $24 \mathrm{~h}$ of culture (Figs. 1

229

A-F). The in situ proliferation index of pamidronate-treated RAW 264.7 cells was $73.1 \pm$ 230

$2.32 \%$ at $24 \mathrm{~h}, 74.7 \pm 2.8 \%$ at $48 \mathrm{~h}$, and that of non-treated RAW 264.7 cells was 69.9 231

$\pm 2.46 \%$ by the in situ proliferation assay (Fig. $1 \mathrm{G}$ ). These results indicate pamidronate 232 slightly elevated mitosis of RAW 264.7 cells, murine macrophages, by $3.2 \%$ in $24 \mathrm{~h}$ and 233 $4.8 \%$ in $48 \mathrm{~h}$ of culture.

Effects of pamidronate on the expressions of proliferation-related proteins in

RAW 264.7 cells

RAW 264.7 cells treated with $6.5 \mu \mathrm{M}$ pamidronate for 12,24 , or 48 h exhibited 
239 nuclear antigen (PCNA, 4\%), cyclin dependent kinase 4 (CDK4, 10.1\%), mitosis phase

240 promoting factor (MPF) recognized by a mitosis-specific monoclonal antibody (MPM-2 ,

241 10.7\%), polo-like kinase 4 (PLK4, 7.3\%), cyclin D2 (4.9\%), and lamin A/C (8.7\%) and

242 also increases in proliferation-inhibiting proteins, p14 (21.1\%), p15/16 (14\%), p27

$243(18.7 \%)$ levels versus non-treated controls. These expressional changes of proliferation244 activating proteins became noticeable after 24 and $48 \mathrm{~h}$ of pamidronate treatment but 245 remained at $< \pm 15 \%$, but the proliferative activity of RAW 264.7 cells was limited by the 246 increase of protein expressions of proliferation-inhibiting proteins (Figs. $2 \mathrm{~A}$ and B).

247 These results suggest pamidronate might have a mild proliferative effect on RAW 264.7 248 cells.

Effects of pamidronate on the expressions of cMyc/MAX/MAD network proteins in RAW 264.7 cells

The expressions of cMyc and MAX decreased by $12.6 \%$ and $7.9 \%$, respectively, 253 after $12 \mathrm{~h}$ of pamidronate treatment and consistently decreased by $7.4 \%$ and $1.8 \%$, respectively, at $48 \mathrm{~h}$ versus non-treated controls, whereas MAD-1 expression decreased by a maximum of $15.7 \%$ after $12 \mathrm{~h}$ of treatment and slightly increased by $1.7 \%$ at $48 \mathrm{~h}$. On the other hand, p27 expression increased by $18.7 \%$ after $48 \mathrm{~h}$ of 257 treatment (Figs. $2 \mathrm{C}$ and D). These results indicate pamidronate suppressed cMyc/MAX/MAD network expressions and resulted low level of Myc-Max heterodimers which are strongly binding to E-box (CACGTG). These expressional changes of cMyc/MAX/MAD network proteins may negatively contribute to the proliferative effect of 261 pamidronate on RAW 264.7 cells. 
263 Effects of pamidronate on the expressions of p53/Rb/E2F signaling proteins in 264 RAW 264.7 cells

Pamidronate increased the expression of p53 in RAW 264.7 cells by $14.5 \%$ at $12 \mathrm{~h}$ 266 but its increase was diminished by $8.7 \%$ at $48 \mathrm{~h}$ versus non-treated controls, and 267 decreased the expression of negative regulator of $\mathrm{p} 53, \mathrm{MDM} 2$, by $4.3 \%$ at $12 \mathrm{~h}$. Rb-1 268 expression was also slightly increased by $7.9 \%, 7.3 \%, 15.8 \%$ at 12,24 , and $48 \mathrm{~h}$, 269 respectively. Notably, the expression of CDK4, activator of Rb-1 was increased by 270 $16.6 \%$ at $12 \mathrm{~h}$, although p21, CDK inhibitor was also increased by $11 \%$ at $12 \mathrm{~h}$ 271 concurrent with the elevation of p53 expression. Resultantly, the expression of the 272 objective transcription factor, E2F-1, increased by $12.8 \%$ at $24 \mathrm{~h}$ and by $9.1 \%$ at $48 \mathrm{~h}$ 273 (Figs. $2 \mathrm{E}$ and $\mathrm{F}$ ). This up-regulation of $\mathrm{p53/Rb/E2F}$ signaling by pamidronate may 274 indicate the increase in the level of Rb-1 phosphorylation and positively affect RAW 275264.7 cell proliferation.

Effects of pamidronate on the expressions of Wnt/B-catenin signaling proteins in 278 RAW 264.7 cells

The expressions of Wnt1, $\beta$-catenin, and adenomatous polyposis coli (APC) in RAW 280 264.7 cells were increased by $25.2 \%, 12.9 \%$, and $8.7 \%$, respectively, by pamidronate at $24 \mathrm{~h}$ versus non-treated controls, while the expression of E-cadherin was reduced by 282 $13.8 \%$ coincident with slight increase of snail expression by $2.2 \%$ at $48 \mathrm{~h}$. Resultantly, 283 the expression of the objective transcription factor T-cell factor 1 (TCF-1) was increased by $9.3 \%$ at $12 \mathrm{~h}$ and by $13.3 \%$ at $48 \mathrm{~h}$ (Figs. $2 \mathrm{G}$ and $\mathrm{H}$ ). These findings regarding the 
285 286 287 288 289 290 291 292 293 294 295 296 297 298 299 300 301 302 303 304 305 306 307

up-regulation of Wnt/ $\beta$-catenin signaling and downregulation of E-cadherin by pamidronate may have significantly increased RAW 264.7 proliferation.

\section{Effects of pamidronate on the expressions of epigenetic modification-related} proteins in RAW 264.7 cells

Histone $\mathrm{H} 1$ expression increased in pamidronate treated cells to $131.3 \%$ at $24 \mathrm{~h}$ and to $122.3 \%$ at $48 \mathrm{~h}$ versus non-treated controls. Regarding histone modification, the expression of lysine-specific demethylase 4D (KDM4D) was $5 \%$ lower at $24 \mathrm{~h}$, but that of histone deacetylase 10 (HDAC10) showed little change. With respect to DNA modification, DNA (cytosine-5)-methyltransferase 1 (DNMT1) expression was 10.4\% higher at $48 \mathrm{~h}$ and those of DNA methyltransferase 1-associated protein 1 (DMAP1) and methyl-CpG binding domain 4 (MBD4) were $18.2 \%$ and $15.9 \%$ higher at $24 \mathrm{~h}$, respectively, and were maintained at $8.6 \%$ and $21 \%$ higher at $48 \mathrm{~h}$ (Figs. $3 \mathrm{~A}$ and B). These results suggest pamidronate increased histone and DNA methylation and subsequently hindered DNA transcription in RAW 264.7 cells, and that this epigenetic effect of pamidronate might be related to the down-regulation of various proteins.

\section{Effects of pamidronate on the expressions of translation-related proteins in RAW}

\section{7 cells}

RAW 264.7 cells treated with pamidronate showed gradual reductions in protein translation-related protein levels versus non-treated controls. Although deoxyhypusine hydroxylase (DOHH) expression slightly increased by $17 \%$ and $5.4 \%$ after 24 and $48 \mathrm{~h}$ of treatment, respectively, deoxyhypusine synthase (DHS) expression was consistently 
308 reduced by $18.8 \%$ and $16.8 \%$, respectively, at these times. The protein expressions of 309 objective factors of protein translation, that is, eukaryotic translation initiation factor $5 \mathrm{~A}-1$

310 (elF5A-1) and elF5A-2, were also reduced by $2.9 \%$ and $3.2 \%$ at $48 \mathrm{~h}$, respectively,

311 while that of eukaryotic translation initiation factor 2- $\alpha$ kinase 3 (elF2AK3; an inactivator 312 of elF2) was increased by $6.8 \%$ at $24 \mathrm{~h}$ (Figs. $3 \mathrm{C}$ and D). We considered that the 313 pamidronate-induced reductions in the expressions of translation-related proteins might 314 cause global inactivation of cellular signaling. However, changes in the levels of these 315 protein levels which are normally abundant in cells tended to remain at $< \pm 15 \%$ after 48 $316 \mathrm{~h}$ of pamidronate treatment.

\section{Effects of pamidronate on the expressions of growth factor-related proteins in} RAW 264.7 cells

RAW 264.7 cells treated with pamidronate for $48 \mathrm{~h}$ showed increases in the 321 expressions of growth hormone (by $\mathrm{GH}, 13.5 \%$ ), growth hormone-releasing hormone 322 (GHRH, 6.6\%), platelet-derived growth factor-A (PDGF-A, 13.2\%), insulin-like growth factor-1 (IGF-1, 12.8\%), IGF-2 receptor (IGFIIR, 22.5\%), epidermal growth factor receptor (ErbB-1, HER1, 19.2\%), HER2 (receptor tyrosine-protein kinase ErbB-2 , $13 \%)$, transforming growth factor- $\beta 1$ (TGF- $\beta 1,16.4 \%)$, TGF- $\beta 2$ (27.7\%), TGF- $\beta 3$ 326 (20.7\%), SMAD4 (18.4\%), fibroblast growth factor-7 (FGF-7 known as a keratinocyte 327 growth factor, $20.7 \%$ ), and estrogen receptor $\beta$ (ER $\beta, 14 \%)$ over $48 \mathrm{~h}$ versus non328 treated controls whereas the expressions of FGF-1, FGF-2, and CTGF decreased by 329 $14 \%, 13.9 \%$, and $9.6 \%$, respectively. The expressions of other growth factor-related proteins, including those of hepatocyte growth factor $\alpha$ (HGFa) and Met, changed 
331 minimally (by $\pm 5 \%$ ) like the expressions of housekeeping proteins (Figs. $3 E$ and $F$ ).

332 These results indicate pamidronate influenced the expressions of many growth factors

333 necessary for the growth and differentiation of RAW 264.7 cells, that is, it increases the

334 expressions of GH, GHRH, PDGF-A, IGF-1, IGFIIR, HER1, HER2, TGF- $\beta 1$, TGF- $\beta 2$,

335 TGF- $\beta 3$, SMAD4, FGF-7, and ER $\beta$, while reduces the expressions of extracellular

336 matrix maturation, that is, FGF-1, FGF-2, and CTGF.

337

338

339

Effects of pamidronate on the expressions of RAS signaling proteins in RAW

264.7 cells

340

Although many RAS upstream signaling proteins were upregulated by pamidronate,

341

RAS downstream effector proteins were significantly downregulated. The increase in

342 the expressions of KRAS (by $16.8 \%$ ), NRAS (7.7\%), HRAS (12.6\%),

343 phosphatidylinositol 3-kinase (PI3K, 12.3\%), Jun N-terminal protein kinase-1 (JNK-1,

$34412.4 \%$ ), mammalian target of rapamycin (mTOR, 14.2\%), phosphatase and tensin

345 homolog (PTEN, 11.2\%), RAF-B (serine/threonine-protein kinase B-Raf, 18\%), Rab 1

346 (GTPase, 10.5\%), neurofibromin 1 (NF-1, 16\%), protein kinase C (PKC, 10\%), p-PKC

$347(14 \%)$, son of sevenless homolog 1 (SOS-1, 22.7\%), SOS-2 (14.1\%), and signal

348 transducer and activator of transcription-3 (STAT3, 7.2\%) were found over $48 \mathrm{~h}$ of

349 treatment versus non-treated controls, while RAS downstream expressions of

350 pAKT1/2/3, 5' AMP-activated protein kinase (AMPK), extracellular signal-regulated

351 kinase 1 (ERK-1), and p-ERK-1 were decreased by $8.8 \%, 2.9 \%, 7.9 \%$, and $8 \%$,

352 respectively. And the expressions of A-kinase anchoring protein (AKAP) and caveolin-1

353 were also reduced by $16.6 \%$ and $15.4 \%$, respectively (Figs. $3 \mathrm{G}$ and $\mathrm{H}$ ). These results 
354 indicate pamidronate significantly reduced the expressions of the downstream effector 355 proteins, ERK-1 and p-ERK-1, albeit many upstream proteins (KRAS, NRAS, HRAS, 356 PI3K, JNK-1, mTOR, PTEN, RAF-B, Rab 1, NF-1, PKC, p-PKC, SOS-1, SOS-2, and 357 STAT3, and thus, suggest RAS signaling (a major signal for cellular growth) was 358 gradually attenuated in RAW 264.7 macrophages.

359

360

\section{Effects of pamidronate on the expressions of NFkB signaling proteins in RAW}

\section{7 cells}

Pamidronate had different effects on the expressions of NFkB signaling proteins in

RAW 264.7 cells. The expressions of NFkB upstream signaling proteins were increased

by pamidronate, that is; nuclear factor kappa-light-chain-enhancer of activated B cells

365

(NFkB, by $11 \%$ ), PTEN (11.2\%), mTOR (14.2\%), peroxisome proliferator-activated

366

receptor gamma coactivator 1- $\alpha$ (PGC-1 $\alpha, 10.4 \%)$, and nuclear factor (erythroid-derived 367

2)-like 2 (NRF2, 12.1\%), while the expressions of NFkB downstream effector proteins, pAKT1/2/3, growth arrest and DNA damage 45 (GADD45), GADD153, p38, p-p38, steroid receptor coactivator-1 (SRC1), and multi-drug resistance (MDR) were reduced by $8.8 \%, 13.4 \%, 17.3 \%, 10.2 \%, 10.2 \%, 15.5 \%$, and $19.1 \%$, respectively. The expression of ikappaB kinase (IKK) expressions was decreased by $15.5 \%$ after $48 \mathrm{~h}$ of 372 treatment, and those of tumor necrosis factor $\alpha$ (TNF $\alpha)$ and activating transcription 373 factor 6 (ATF6) only decreased by $<5 \%$. These results indicate the expressions of 374 many proteins that enhance NFkB signaling tended to be downregulated by treatment 375 with pamidronate for $48 \mathrm{~h}$, that is, pAKT1/2/3, GADD45, GADD153, p38, p-p38, SRC1, 376 MDR, and more, proteins suppressing NFkB signaling tended to be upregulated by 
377 pamidronate, that is, PTEN, mTOR, PGC-1 $\alpha$, and NRF2 (Figs. 4 A and B). These

378 results indicate pamidronate effectively suppressed NFkB signaling in RAW 264.7 cells.

379

380 Effects of pamidronate on the expressions of upregulated inflammatory proteins 381

\section{in RAW 264.7 cells}

The proteins upregulated by pamidronate were; CD3 (a T cell co-receptor 383 constituting T cell receptor (TCR) complex, by $21.6 \%$ ), CD4 (a co-receptor of the T cell 384 receptor (TCR), 12\%), neural cell adhesion molecule (NCAM, CD56, detecting natural 385 killer cells, gamma delta ( $(\bar{\delta})$ T cells, activated CD8+ T cells, and dendritic cells, 32.8\%),

CD80 found on the surface of dendritic cells, B cells, monocytes and antigen-presenting cells (16.9\%), programmed cell death protein 1 (Pdcd-1/1, CD279, 18.9\%), IL-8 (a 388 chemoattractant cytokine, 18.3\%), IL-12 (a T cell-stimulating factor, 11.4\%), MMP-3 stromelysin-1 involved in wound repair, progression of atherosclerosis, and tumor initiation (17.7\%), MMP-9 (a regulating factor for neutrophil migration, angiogenesis, and wound repair, 13.3\%), MMP-12 (a macrophage metalloelastase contributing to elastin degradation, 10.4\%), cathepsin C (a lysosomal exo-cysteine protease degrading various extracellular matrix components, $21.6 \%$ ), C-X-C chemokine receptor type 4 (CXCR4, 17\%), monocyte chemotactic protein-1 (MCP-1, an eotaxin, 33.5\%), cyclooxygenase 2 (COX2, an important mediator of inflammation, 13.8\%), versican (a large extracellular matrix proteoglycan that is involved with tissue homeostasis and inflammation, 26.5\%), and kininogen (a constituent of the blood coagulation system as well as the kinin-kallikrein system, 13\%) (Figs. $4 \mathrm{C}$ and D). 
These results indicate pamidronate stimulated cell-mediated immunity and chronic 400 inflammation by upregulation of CD3, CD4, NCAM, CD80, Pdcd-1/1, IL-8, IL-12, MMP401 3, MMP-9, MMP-12, cathepsin C, CXCR4, MCP-1, COX2, versican, and kininogen in 402 RAW 264.7 cells.

403

\section{Effects of pamidronate on the expressions of downregulated inflammatory} proteins in RAW 264.7 cells

Proteins downregulated were tumor necrosis factor a (TNFa, by $11.6 \%)$, IL-1a (a 407 "dual-function cytokine", which means it plays a role in the nucleus by affecting transcription, apart from its extracellular receptor-mediated effects as a classical 409 cytokine, $24.1 \%$ ), IL-6 (an important mediator of fever and of the acute phase response, 8.6\%), IL-10 (an anti-inflammatory cytokine, $15.2 \%$ ), IL-28 which play a role in the adaptive immune response (6\%), B-lymphocyte antigen CD20 (6\%), CD28 which is necessary for T cell activation and survival (6.8\%), PECAM-1 (CD31, a role for leukocyte transmigration, angiogenesis, and integrin activation, 11.3\%), CD34 (a 414 transmembrane phosphoglycoprotein protein which is expressed in early hematopoietic 415 and vascular-associated tissues, 25.4\%), CD40 (a costimulatory protein found on 416 antigen presenting cells, 8.5\%), intercellular adhesion molecule 1 (ICAM-1, CD54, $41719.8 \%$ ), CD68 (a marker for the various cells of the macrophage lineage, 21.6\%), CD99 418 (MIC2, a heavily O-glycosylated transmembrane protein which is expressed in all 419 leukocytes, 7.6\%), vascular cell adhesion molecule-1 (VCAM, CD106, a role in 420 leukocyte-endothelial cell signal transduction, 12.7\%), cathepsin G (an important role in 421 eliminating intracellular pathogens and breaking down tissues at inflammatory sites, 
$4227.8 \%$ ), cathepsin $\mathrm{K}$ (a lysosomal cysteine protease involved in bone remodeling and 423 resorption, $27.9 \%$ ), COX1 (prostaglandin G/H synthase 1 involved in cell signaling and 424 maintaining tissue homeostasis, $15 \%$ ), lysozyme (17.1\%), macrophage colony425 stimulating factor (M-CSF, 16.1\%), MMP-1 (an interstitial collagenase, 23.3\%), MMP-2 426 (a role for lymphangiogenesis, 22\%), MMP-10 (stromelysin-2, 14.1\%), leukotriene A4 427 hydrolase (LTA4H, 4.9\%), cathelicidin antimicrobial peptides LL-37 (an antimicrobial 428 peptide, 23.6\%), $\alpha 1$-antitrypsin (a protease inhibitor, 22.1\%), $\beta$-defensin 1 (a 429 microbicidal and cytotoxic peptide, 7.4\%), $\beta$-defensin 2 (a microbicidal and cytotoxic 430 peptide, $4.8 \%$ ), and $\beta$-defensin 3 (a microbicidal and cytotoxic peptide, $7.6 \%$ ) over $48 \mathrm{~h}$ 431 of pamidronate treatment (Figs. $4 \mathrm{E}$ and F).

432 These results indicate pamidronate inhibited innate immunity, immediate 433 inflammatory rection, and wound repair processes by downregulation of TNFa, IL-1a, 434 IL-6, IL-10, IL-28, CD20, CD28, PECAM-1, CD34, CD40, CD68, CD99, VCAM, 435 cathepsin G, cathepsin K, COX1, lysozyme, M-CSF, MMP-1, MMP-2, MMP-10, LTA4H, 436 LL-37, $\alpha 1$-antitrypsin, $\beta$-defensin 1, $\beta$-defensin 2 , and $\beta$-defensin 3 in RAW 264.7 cells.

Effects of pamidronate on the expressions of p53-mediated apoptosis-related proteins in RAW 264.7 cells

Pamidronate affected the expressions of p53-mediated apoptosis-related proteins, 441 particularly p53 protein, which was increased by $14.5 \%$ after treatment for $24 \mathrm{~h}$, while 442 the expression of E3 ubiquitin-protein ligase MDM2 was decreased by $4.3 \%$ at $12 \mathrm{~h}$ 443 versus non-treated controls. After treatment for $48 \mathrm{~h}$, the expressions of pro-apoptotic 444 proteins, Bcl-2-associated death promoter (BAD), Bcl-2 homologous antagonist/killer 
445 (BAK), pro-apoptotic member of the Bcl-2 protein family NOXA, apoptosis regulator 446 BAX, and apoptosis inducing factor (AIF) were decreased by $12.4 \%, 12.2 \%, 26.6 \%$, $44723.5 \%$, and $16 \%$, respectively, but the expressions of p53 upregulated modulator of 448 apoptosis (PUMA) and apoptotic protease activating factor 1 (APAF-1) were increased 449 by $12.4 \%$ and $5.4 \%$. The expressions of apoptosis executor proteins, caspase 9 , c450 caspase 9 , caspase 3, c-caspase 3 , and poly [ADP-ribose] polymerase 1 (PARP-1) 451 increased by $28 \%, 20.9 \%, 27.5 \%, 14.6 \%$, and $26.5 \%$ at $48 \mathrm{~h}$, whereas that of cleaved 452 PARP-1 (c-PARP-1) was reduced by $18.2 \%$ at $24 \mathrm{~h}$. On the other hand, the expression 453 of the anti-apoptosis protein, BCL2 gradually decreased by $12.9 \%$ at $48 \mathrm{~h}$ (Figs. $5 \mathrm{~A}$ and B). These results indicate pamidronate induced PARP-1/caspase 9/caspase 3-mediated 455 apoptosis independently of p53/BAX and AIF signalings and in RAW 264.7 cells, which suggests pamidronate might induce PARP-1-mediated non-apoptotic cell death.

\section{Effects of pamidronate on the expressions of FAS-mediated apoptosis-related}

RAW 264.7 cells treated with pamidronate showed increases in the expressions of FAS-mediated apoptosis-related proteins as compared with non-treated controls. After

462 treatment with pamidronate for $48 \mathrm{~h}$, the expressions of death receptors on cell 463 surfaces, that is, of FAS, FAS ligand (FASL), and FAS-associated protein with death 464 domain (FADD), were increased by $4.6 \%, 15.3 \%$, and $24.4 \%$, respectively, and those of 465 caspase 8 , caspase 3, and c-caspase 3 were also increased by $30.8 \%, 27.5 \%$, and $46614.6 \%$, respectively. On the other hand, the expressions of FLICE-like inhibitory protein 467 (FLIP) and $\mathrm{BH} 3$ interacting-domain death agonist (BID) were minimally changed (< 
$468 \pm 5 \%$ ) (Figs. $5 \mathrm{C}$ and D). These findings indicate pamidronate might induce apoptosis via 469 caspase 8 and 3 through FASL/FAS/FADD signaling in RAW 264.7 cells.

470

471 Effects of pamidronate on the expressions of cell survival-related proteins in

472

RAW 264.7 cells

473

RAW 264.7 cells treated with pamidronate showed variable changes in the 474 expressions of cell survival-related proteins as compared with non-treated controls. The 475 expressions of PTEN, telomerase reverse transcriptase (TERT), NRF2, PGC-1a, PKC, 476 p-PKC, and focal adhesion kinase (FAK) were increased by $11.2 \%, 8.6 \%, 12.1 \%$, $10.4 \%, 10 \%, 14 \%$, and $13.7 \%$, respectively, after $48 \mathrm{~h}$ of pamidronate treatment, while 478 those of pAKT1/2/3, survivin, BCL2, p38, p-p38, and SP-1 were reduced by $9.1 \%$, 479 $10.9 \%, 12.9 \%, 10.2 \%, 10.2 \%$, and $9.6 \%$, respectively. On the other hand, the 480 expressions of SP-3, AMPK, and ATF6 hardly changed ( $< \pm 5 \%)$ (Figs. $5 \mathrm{E}$ and F). These results suggested cell survival was enhanced by the up-regulations of NRF2/PGC-1 $\alpha$ and PKC/FAK signaling, which are features of mitochondrial biogenesis 483 and the signal transduction cascade, respectively, but reduced by the down-regulations of $\mathrm{AKT} /$ survivin/BCL2 and p38/SP-1 signalings, which are features of cell exposure to stressors, such as oxidative damage. These results suggest that pamidronate increases energy metabolism and signal transduction in RAW 264.7 cells, but that the abilities of their cells to overcome different cytological stressors is relatively poor. 
The expressions of cell protection-related proteins in RAW 264.7 cells were 492 increased by pamidronate; heat shock protein-70 (HSP-70) by $21.7 \%$ at $12 \mathrm{~h}, 1$ 493 phosphatidylinositol-4,5-bisphosphate phosphodiesterase $\beta-2$ (PLC- $\beta 2$ ) by $30.6 \%$ at 48 $494 \mathrm{~h}, \mathrm{PI} 3 \mathrm{~K}$ by $12.3 \%$ at $48 \mathrm{~h}$, master regulator of mitochondrial biogenesis PGC-1a by 495 $10.4 \%$ at $12 \mathrm{~h}$, mitogen-activated protein kinase JNK-1 by $12.4 \%$ at $48 \mathrm{~h}$, PKC by $10 \%$ 496 at $48 \mathrm{~h}, \mathrm{p}-\mathrm{PKC}$ by $14 \%$ at $12 \mathrm{~h}$, focal adhesion kinase (FAK) by $13.7 \%$ at $24 \mathrm{~h}$, mucin 1 497 by $3.3 \%$ at $48 \mathrm{~h}$, and mucin 4 by $10.8 \%$ at $24 \mathrm{~h}$ versus non-treated controls, whereas 498 the expressions of HSP-27, HSP-90, and 5'AMP-activated protein kinase (AMPK) were 499 decreased by pamidronate; by $3.6 \%$ at $48 \mathrm{~h}$, by $12.7 \%$ at $12 \mathrm{~h}$, and by $2.9 \%$ at $12 \mathrm{~h}$, 500 respectively.

$501 \quad$ The expressions of anti-oxidative proteins in RAW 264.7 cells were increased by 502 pamidronate; detoxifying enzyme glutathione S-transferase $\omega 1$ (GSTO1) by $9.9 \%$ at 24 $503 \mathrm{~h}$, autophagy substrate LC3 by $30.9 \%$ at $12 \mathrm{~h}$, NRF2 by $12.1 \%$ at $24 \mathrm{~h}$, while the 504 expressions of Cu-Zn superoxide dismutase-1 (SOD-1), nitric oxide synthase 1 (NOS1), 505 heme oxygenase $1(\mathrm{HO}-1)$, and endoplasmic reticulum (ER) stress-regulated 506 transmembrane transcription factor ATF6 were decreased by pamidronate; by $13 \%$ at $50724 \mathrm{~h}$, by $19.2 \%$ at $48 \mathrm{~h}$, by $5.5 \%$ at $48 \mathrm{~h}$, and by $5.5 \%$ at $48 \mathrm{~h}$, respectively. And sodium508 dependent vitamin C transporter 2 (SVCT2) and cross-linking enzyme transglutaminase 5092 (TGase-2) were decreased by $11.1 \%$ and $14.6 \%$ at $12 \mathrm{~h}$, respectively, but gradually 510 increased by $8.1 \%$ and $17.6 \%$ at 48 h, respectively (Figs. 6 A and B).

511 Although RAW 264.7 cells treated with pamidronate appeared to be silent, as they 512 exhibited reduced NFkB signaling and had low levels of antioxidant-related proteins, 513 SOD-1, NOS1, and HO-1 in their cytoplasms, they had higher levels of the cell 
514 protection-related proteins, HSP-70, PLC- $\beta 2$, PI3K, PGC-1 $\alpha$, JNK-1, PKC, p-PKC, FAK,

515 and mucin 1 and 4 than non-treated controls. These observations suggest the

516 expressions of cellular protection-related proteins, such as those involved in

517 detoxification and autophagy, are upregulated by pamidronate in RAW 264.7 cells

518 despite reduced RAS and NFkB signalings.

519

520

Effects of pamidronate on the expressions of differentiation-related proteins in

521

522

523

524

525

526

527

528

529

530

531

532

533

534

535

536

\section{RAW 264.7 cells}

RAW 264.7 cells treated with pamidronate for $48 \mathrm{~h}$ showed increases in the expressions of the differentiation-related proteins p63 (25.4\%), vimentin (39.8\%), transglutaminase 2 (TGase-2, 17.6\%), PLC- 32 (30.6\%), PI3K (12.3\%), PKC (10\%), pPKC (14\%), FAK (20.7\%), integrin a5 (21\%), neural cell adhesion molecule (NCAM, CD56, 32.9\%), cysteine rich protein-1 (CyRP-1, 19.6\%), AP-1 complex subunit mu-1 (AP1M1, 12.8\%), transcription factor SP-3 (5.3\%), sonic hedgehog (SHH, 22\%), and S$100(27.1 \%)$ as compared with non-treated controls, but reductions in the expressions of the differentiation-related proteins, caveolin-1 (15.4\%), $\alpha$-actin $(10.8 \%)$, intercellular adhesion molecule 1 (ICAM-1, CD54, 19.8\%), homing cell adhesion molecule (HCAM, CD44, 27.5\%), platelet endothelial cell adhesion molecule 1 (PECAM-1, CD31, 11.3\%), receptor for sonic hedgehog PTCH-1 (12.9\%), transcription factor SP-1 (9.6\%), and cystatin A (28.9\%) (Figs. 6 C and D).

The proteins essential for the differentiation, migration, adhesion, and endocytosis of RAW 264.7 cells, that is, p63, vimentin, TGase-2, PLC- $\beta 2$, PI3K, PKC, p-PKC, FAK, integrin a5, NCAM (CD56), CyRP-1, SP-3, SHH, and S-100 were upregulated by 
537 treatment with pamidronate for $48 \mathrm{~h}$, whereas some proteins required for further

538 differentiation into active macrophages or dendritic cells, that is, caveolin-1, $\alpha$-actin,

539 ICAM-1 (CD54), HCAM (CD44), PECAM-1 (CD31), PTCH-1, SP-1, and cystatin A, were

540 downregulated. These observations suggest pamidronate-treated RAW 264.7 cells

541 maintain major signal transduction organelles for cellular proliferation and protection but

542 are defective in terms of advanced cytological differentiation due to reductions in the

543 expressions of caveolin-1, a-actin, PTCH-1, and SP-1.

544

545 Effects of pamidronate on the expressions of oncogenic proteins in RAW 264.7

546 cells

547 RAW 264.7 cells treated with pamidronate showed increases in the expressions of

548 the oncogenic proteins, carcinoembryonic antigen (CEA, 21.2\%), conserved regulatory

549 molecule 14-3-3 (31.4\%), deleted in malignant brain tumors 1 protein (DMBT1, 22.8\%),

550 telomerase reverse transcriptase (TERT, 8.6\%), transmembrane subunit containing

551 three EGF-like domains mucin 4 (10.8\%), and serine protease inhibitor maspin (22.7\%)

552 as compared with non-treated controls, and also increases in the expressions of the

553 tumor suppressor proteins, phosphatase and tensin homolog (PTEN, 11.2\%), mTOR

554 (14.2\%), GTPase-activating protein neurofibromin 1 (NF-1, 16\%), breast cancer type 1

555 susceptibility protein (BRCA 1, 16\%), BRCA 2 (6.3\%), and methyl-CpG binding protein-

5564 (MBD4, 21\%). Whereas the expressions of strong oncogenic proteins, BCL2, SP-1,

557 proto-oncogene serine/threonine-protein kinase PIM-1, and Yes-associated protein

558 (YAP) were reduced by $12.9 \%, 9.6 \%, 17.4 \%$, and $34.3 \%$, respectively, after treatment 
559 for $48 \mathrm{~h}$. In addition, the expression of tumor suppressor protein ATM was also 560 diminished by $5.2 \%$ after treatment for $12 \mathrm{~h}$ (Figs. $6 \mathrm{E}$ and F).

561 Concomitant increases in the expressions of oncogenic proteins and tumor 562 suppressor proteins indicate RAW 264.7 cells were stimulated by pamidronate and 563 reacted by initiating oncogenic signaling for cellular proliferation, survival, and 564 apoptosis.

565

566

Effects of pamidronate on the expressions of angiogenesis-related proteins in

567

568

569

570

571

572

573

574

575

576

577

578

579

580

581

\section{RAW 264.7 cells}

RAW 264.7 cells treated with pamidronate showed rapid reductions in the expressions of angiogenesis-related proteins, as follows, HIF-1a (12\%), angiogenin (13.2\%), vascular endothelial growth factor A (VEGF-A, 14.7\%), VEGFR2 (12.5\%), pVEGFR2 (22.1\%), von Willebrand factor (VWF, 16\%), capillary morphogenesis protein 2 (CMG2, 18.5\%), COX1 (11.6\%), FGF-1 (14\%), FGF-2 (13.9\%), MMP-2 (22\%), MMP-10 (14.1\%), plasminogen activator inhibitor-1 (PAI-1, 12.4\%), PECAM-1 (CD31, 11.3\%), and vascular cell adhesion molecule-1 (VCAM-1, CD106, 12.7\%) after treatment with pamidronate for $48 \mathrm{~h}$ versus non-treated controls. The expressions of endothelin 1 (21amino acid vasoconstricting peptide, ET-1) and PDGF-A were increased by $18.6 \%$ and $13.2 \%$, respectively, whereas the expressions of VEGF-C, lymphatic vessel endothelial hyaluronan receptor 1 (LYVE-1), Fms-related tyrosine kinase 4 (FLT-4), and plasminogen barely changed $(< \pm 5 \%)$ (Figs. $7 \mathrm{~A}$ and $\mathrm{B}$ ).

Among the angiogenesis-related proteins, the expressions of the blood vesselforming proteins, angiogenin, VEGF-A, VEGFR2, vWF, and CMG2 were markedly 
582 reduced by pamidronate, while those of the lymphatic vessel-forming proteins, VEGF-C

583 and LYVE-1 tended to increase slightly $(<5 \%)$. Pamidronate also reduced the

584 expressions of the extracellular matrix proteins, FGF-1, FGF-2, MMP-2, and MMP-10,

585 which are required for de novo angiogenesis and wound healing. These results suggest

586 pamidronate significantly suppresses the expressions of angiogenesis-related proteins

587 in RAW 264.7 cells, and that it might be able to potently inhibit blood vessel formation in 588 vivo.

589

590 Effects of pamidronate on the expressions of osteogenesis-related proteins in

591

592

593

594

595

596

597

598

599

600

601

602

603

604

\section{RAW 264.7 cells}

Treatment with pamidronate for $48 \mathrm{~h}$ decreased the expressions of the osteogenesis-related proteins; osteoprotegerin (OPG, 30.7\%), osterix (4.5\%), mammalian Runt-related transcription factor 2 (RUNX2, 23.8\%), osteocalcin (16.2\%), and connective tissue growth factor (CTGF, 9.6\%) and those of the osteoclastogenesisrelated proteins; receptor activator of nuclear factor kappa-B ligand (RANKL, 31.6\%), cathepsin K (27.9\%), and HSP-90 (12.7\%) versus non-treated controls. On the other hand, the expressions of osteopontin and TGF- $\beta 1$ were increased by pamidronate by $19.4 \%$ and $16.4 \%$ and the expressions of bone morphogenetic protein-2 (BMP-2, 8.3\%), BMP-3 which negatively regulates bone density (16.8\%), BMP-4 (6.8\%), osteonectin (5.7\%), and alkaline phosphatase (ALP, 5.3\%), tended to be increased (Figs. $7 \mathrm{C}$ and D).

The expressions of the major osteoblast differentiation proteins; OPG, osteocalcin, and RUNX2, and of the osteoclast differentiation proteins; RANKL, HSP-90, and 
605 cathepsin $\mathrm{K}$, were markedly reduced by $48 \mathrm{~h}$ of pamidronate treatment, whereas the 606 expressions of the bone matrix proteins, osteopontin, BMP-2, BMP-4, osteonectin, and

607 ALP tended to increase. In particular, the expressions of BMP-3 (an antagonist to other 608 BMP's in the differentiation of osteogenic progenitors) and TGF- $\beta 1$ (an inhibitor of 609 osteoclast activity) were markedly increased by pamidronate treatment. These results 610 suggest pamidronate-treated RAW 264.7 cells are hardly differentiated into osteoclasts 611 and give sparse influence on adjacent osteoblastic cells by expression of bone matrix 612 proteins.

613

614 Global protein expressions in pamidronate-induced RAW 264.7 cells

615 Global protein expression changes of representative proteins $(n=73)$ from above 19 616 different protein signaling pathways are illustrated as a star plot in Fig. 8. Although 617 pamidronate is low molecular weight entity, it was found to widely affect the expressions 618 of proteins in different signaling pathways in RAW 264.7 cells. In particular, pamidronate 619 inactivated epigenetic modification and protein translation and subsequently down620 regulated the expressions of some proteins required for the proliferation, differentiation, 621 protection, and survival of RAW 264.7 cells.

622 The increases observed in the expressions of proliferation-related proteins were 623 presumably related to the up-regulations of $\mathrm{p} 53 / \mathrm{Rb} / \mathrm{E} 2 \mathrm{~F}$ and $\mathrm{Wnt} / \beta$-catenin signaling by 624 pamidronate albeit suppression of cMyc/MAX/MAD network signaling. The suppression 625 of RAS signaling induced by pAKT1/2/3, ERK-1, and p-ERK-1 down-regulations was 626 followed by cMyc/MAX/MAD network down-regulation and by a subsequent inhibition in 627 RAW 264.7 cell proliferation. Furthermore, the marked suppression of NFkB signaling 
628 appeared to be associated with elevation of PARP-1- and FAS-mediated apoptosis and 629 reduction of cellular differentiation, survival, immediate inflammatory reaction, and 630 wound repair.

631 Overall changes in protein expressions induced by pamidronate affected the 632 differentiation of RAW 264.7 cells and resulted in the productions of immature and/or 633 inactive macrophages expressing lower levels of M2 macrophage differentiation 634 proteins (wound healing proteins, TNFa, IL-1a, IL-6, IL-10, PECAM-1, CD99, VCAM, 635 cathepsin G, cathepsin K, COX1, lysozyme, M-CSF, MMP-1, MMP-2, MMP-10, LL-37, $636 \alpha 1$-antitrypsin, $\beta$-defensin $1, \beta$-defensin 2 , and $\beta$-defensin 3 ), angiogenesis-related 637 proteins (HIF-1a, angiogenin, VEGF-A, VEGFR2, p-VEGFR2, VWF, CMG2, COX1, 638 FGF-1, FGF-2, MMP-2, MMP-10, PAI-1, PECAM-1, and VCAM-1), and 639 osteoclast/osteoblast differentiation proteins (OPG, osterix, RUNX2, osteocalcin, and

641 HSP-90) than non-treated controls. Thus, pamidronate-treated RAW 264.7 cells

642 simultaneously exhibited anti-inflammatory, anti-angiogenesis, and bone resorption 643 inhibitive effects. However, the essential protein expression changes for cell 644 proliferation, RAS signaling, and NFkB signaling rarely exceeded $\pm 20 \%$, which suggests 645 pamidronate-treated cells exhibit relatively benign nature and be under homeostatic 646 control.

Highly up- and down-regulated proteins by pamidronate in RAW 264.7 cells

649 In dot graphs plotted with highly up- and down-regulated proteins $(> \pm 10 \%, n=155$, 650 Fig. 9), pamidronate-treated RAW 264.7 cells showed reactive upregulation (10-30\%) of 
651 some proteins for cellular proliferation (CDK4, E2F-1, and TCF-1), protection (HSP-70,

652 LC3, PLC- $\beta 2$, and p-PKC), differentiation (vimentin, NCAM, p63, S-100, and SHH), RAS

653 signaling proteins (KRAS, HRAS, SOS1, SOS2, RAF-B, JNK-1, and Rab), NFkB

654 signaling proteins (NFkB, mTOR, NRF2, PGC-1 $\alpha$, and PTEN), and oncogenic proteins

655 (DMBT1, 14-3-3, and CEA) versus non-treated controls, and were tended to be

656 proliferative but their cellular activities became abortive by the downregulation (10-20\%)

657 of some essential proteins (p14, p15/16, cMyc, MAX, MAD-1, E-cadherin, FGF-1, FGF-

658 2, CTGF, AKAP, caveolin-1, MDR, IKK, GADD45, GADD153, SRC1, and p-p38) and by

659 increases in the expression of histone and DNA methylation-related proteins (histone

$660 \mathrm{H} 1, \mathrm{MBD} 4$, and DMAP1) and by decreases in the expressions of protein translation-

661 related proteins (elF2AK3 and DHS) (Fig. $9 \mathrm{~A}$ and C).

662 On the other hand, pamidronate-treated RAW 264.7 cells appeared to be 663 degenerated by marked downregulation (10-30\%) of M2 macrophage differentiation664 related inflammatory proteins (M-CSF, lysozyme, a1-antitrypsin, CD34, cathepsin K, 665 and MMP-2) and survival-related proteins (BCL2, survivin, SP-1, and p-p38) and by 666 marked upregulation (10-40\%) of apoptosis-related proteins (caspase 9, c-caspase 9, 667 caspase 3, c-caspase 3, PARP-1, p53, and PUMA) versus non-treated controls.

668 Subsequently, the major protein expressions for angiogenesis (VEGF-A, p-VEGFR2, 669 angiogenin, HIF-1 $\alpha$, VCAM-1, FGF-1, FGF-2, PECAM-1, MMP-2, and MMP-10) and 670 osteoclastogenesis (OPG, RANKL, cathepsin K, RUNX2, osteocalcin, and HSP-90)

671 were dramatically suppressed (10-40\%) by pamidronate (Fig. 9 A-C).

672

\section{Discussion}


674

675 Pamidronate is a nitrogen-containing, synthetic bisphosphonate, and its phosphate 676 groups are believed to interfere with phosphorylation processes or interact with proteins 677 in cells (Chen et al. 2012; Nishida et al. 2003; Stefanucci et al. 2015). Pamidronate is 678 not sequestered as a waste material but relatively well adapted in cells, and thus, it is 679 presumed pamidronate is maintained as a metabolite and influences not only the 680 intracellular mevalonate pathway and protein isoprenylation but also signaling 681 molecules and genetic materials (Henneman et al. 2011; Iguchi et al. 2010; Kaiser et al. 682 2013; Tatsuda et al. 2010). It has been shown pamidronate has considerable impact on 683 cells such as macrophages, osteoclasts, and endothelial cells, and that its long-time 684 usage is associated with the risk of BRONJ (Hoefert et al. 2015; Sharma et al. 2016; 685 Zhang et al. 2013). In the present study, we assessed the effects of a therapeutic dose 686 of pamidronate on the expressions of proteins in RAW 264.7 cells by IP-HPLC. As RAW 687264.7 cells are derived from murine macrophages, and their immunological roles to 688 dialysed coffee extract were assessed by IP-HPLC (Yoon et al. 2018b), and this study 689 also explored RAW 264.7 cells for their macrophage roles to pamidronate.

690 Pamidronate-induced proliferation of RAW 264.7 cells was examined by counting 691 cell numbers directly on Petri dishes, and protein expressional changes were 692 determined by IP-HPLC. The in situ proliferation index of pamidronate-treated RAW 693264.7 cells over $24 \mathrm{~h}$ was $73.1 \pm 2.32 \%$, whereas that of non-treated cells was $69.9 \pm$ $6942.46 \%$, thus the pamidronate-induced increase was $3.2 \%$. Furthermore, this increase in 695 in situ proliferation index matched the pamidronate-induced increases in the expressions of different proliferation-related proteins as determined by IP-HPLC. These 
697 data suggest pamidronate can slightly activate mitosis of murine macrophages, RAW 698264.7 cells.

699 When we explored cellular mechanism responsible for altering protein expressions 700 in RAW 264.7 cells, we noticed that the epigenetic environment was generally 701 inactivated by pamidronate due to the up-regulations of DMNT1, MBD4, and DMAP1 702 and the down-regulation of KDM3D, which would tend to increase histone and DNA 703 methylation levels. Protein translation was also inactivated by a marked reduction in

704 DHS expression and an increase in elF2AK3 (an inactivator of elF2) expression versus 705 non-treated controls. We suggest the concurrent inactivations of epigenetic modification 706 and protein translation by pamidronate may have reduced global RAW 264.7 cell 707 activity.

708 Pamidronate-treated RAW 264.7 cells showed a marked reduction in 709 cMyc/MAX/MAD network signaling during culture, and this was followed by the up710 regulation of p27 (a negative regulator of G1 progression) by $16.7 \%$ at $48 \mathrm{~h}$. Whereas

$711 \mathrm{p} 53 / \mathrm{Rb} / \mathrm{E} 2 \mathrm{~F}$ signaling was enhanced by the up-regulations of $\mathrm{p} 53, \mathrm{Rb}-1$, and CDK4 712 resulted in an increase in the expression of the objective transcription factor, E2F-1. 713 Also, Wnt/ $\beta$-catenin signaling was also enhanced by the up-regulations of Wnt-1, $\beta$ 714 catenin, and snail, which led to the up-regulation of the objective transcription factor, 715 TCF-1. As a result, the expressions of the proliferation-activating proteins Ki-67, PCNA, 716 MPM2, CDK4, cyclin D2, and lamin A/C, were increased by pamidronate, and 717 concurrently the expressions of the proliferation-inhibiting proteins p14, p15/16, p21, 718 and p27 were compensatory increased during $48 \mathrm{~h}$ of pamidronate treatment. These 719 results indicate pamidronate-treated RAW 264.7 cells were partly activated and 
720 proliferative due to increased $\mathrm{p} 53 / \mathrm{Rb} / \mathrm{E} 2 \mathrm{~F}$ and $\mathrm{Wnt} / \beta$-catenin signaling despite a

721 marked reduction in cMyc/MAX/MAD network signaling.

722 Pamidronate-treated RAW 264.7 cells showed increases in the expressions of

723 some growth factors and associated proteins, such as IGF-1, IGFIIR, GH, HER1, HER2,

724 TGF- $\beta 1,-\beta 2$, - $\beta 3$, SMAD4, and ER $\beta$, and subsequently, the expressions of upstream

725 RAS signaling proteins including KRAS, HRAS, SOS-1, SOS-2, PI3K, JNK-1, and RAF-

726 B were increased. However, downstreams of AKT and ERK signaling were reduced by

727 the down-regulations of pAKT1/2/3, ERK-1, and p-ERK-1 and by the up-regulations of

728 PTEN and mTOR. Consequently, RAS signaling was attenuated by the down-

729 regulations of pAKT1/2/3, ERK-1, and p-ERK-1 in pamidronate-treated RAW 264.7

730 cells. Therefore, it appeared the pamidronate-induced negative regulation of RAS

731 signaling might significantly reduce the expression of cMyc/MAX/MAD-1 network

732 proteins.

733 Although the expressions of NFkB, NRF2, PGC-1a, PTEN, and mTOR tended to

734 increase $(<10 \%)$ after pamidronate treatment, the expressions of p38, p-p38, GADD45,

735 GADD153, ATF6, MDR, and SRC-1 were reduced after $48 \mathrm{~h}$ of treatment. In addition,

736 the expressions of the reactive oxygen and nitrogen species-related proteins SOD-1,

737 NOS1, and HO-1 were consistently reduced by pamidronate. These observations

738 indicate NFkB signaling was reduced due to pamidronate-induced suppression of the

739 downstream effector protein p38 (p-p38) in RAW 264.7 cells, and that treated cells were

740 less reactive to oxidative or endoplasmic reticulum stress than non-treated controls.

741 Although pamidronate suppressed RAS and NFkB signalings simultaneously, RAW

742264.7 cells expressed higher levels of the protection-related proteins HSP-70, JNK-1, 
743 PLC- 32 , LC3, and FAK, the cell survival-related proteins TERT, NRF2, PGC-1 $\alpha$, p-PKC,

744 and FAK, and the oncogenesis-related proteins CEA, 14-3-3, and DMBT1 than non-

745 treated controls. In particular, increases in the expressions of HSP-70 (protects against

746 thermal and oxidative stress), JNK-1 (a mitogen-activated protein kinase responsible to

747 different stress stimuli), LC3 (autophagosome biogenesis protein), NRF2 (transcription

748 factor for many antioxidant genes), 14-3-3 (a regulator of diverse signaling proteins),

749 DMBT1 (a glycoprotein containing multiple cysteine-rich domains that interact with

750 tumor cells), and TERT (an RNA-dependent polymerase that lengthens telomeres in

751 DNA strands) indicated pamidronate stressed RAW 264.7 cells and stimulated them to

752 respond by expressing protection- and oncogenesis-related proteins.

753 Macrophages constitute a component of the front line of host defense and mediate

754 innate immune responses by triggering; the productions of cytokines, chemokines, and

755 cytotoxic molecules, the mobilizations of cells such as neutrophils and other leukocytes,

756 the phagocytosis of pathogens and their delivery to lysosomes for degradation, and the

757 induction of autophagy (Zhang et al. 2016). Many authors have reported macrophage

758 functions are reduced after pamidronate treatment in vitro and in vivo (Escudero \&

759 Mandalunis 2012; Hoefert et al. 2015; Hoefert et al. 2016a; Mian et al. 1994). In the

760 present study, although the general cytodifferentiation proteins, p63, vimentin, PLC- $\beta 2$,

761 PI3K, PKC, FAK, integrin a5, SHH, and S-100 were upregulated by pamidronate, the

762 M2 macrophage differentiation-related proteins, TNFa, lysozyme, cathepsin G,

763 cathepsin K, M-CSF, ICAM-1, and a1-antitrypsin were consistently downregulated,

764 which suggested pamidronate prevented the differentiation of RAW 264.7 cells into 
765 active M2 macrophages, and resulted retarded wound healing after pamidronate

766 treatment in vivo (Ariza Jimenez et al. 2018; Chen et al. 2018).

767 Pamidronate-treated RAW 264.7 cells also showed increases in the expressions of

768 the apoptosis executor proteins, caspase 8, caspase 3, and c-caspase 3 , which are

769 activated by the FAS-mediated apoptosis signaling cascade, and that the expressions

770 of caspase 9 and c-caspase 9 were also increased by p53 upregulated modulator of

771 apoptosis (PUMA) and APAF-1 even though the expressions of the upstream p53-

772 mediated apoptosis signaling proteins, BAD, BAK, BAX, NOXA, and BCL2 were

773 suppressed. In addition, the expression of PARP-1 was increased by pamidronate

774 whereas the expression of cleaved PARP-1 (c-PARP-1) was decreased. These results

775 suggest pamidronate-treated RAW 264.7 cells underwent FAS/caspase 3/PARP-1-

776 mediated apoptosis, that is, parthanatos, due to the accumulation of polymeric

777 adenosine diphosphate ribose (poly (ADP-ribose) or PAR) caused by severe DNA

778 damage. Actually, pamidronate-treated RAW 264.7 cells were continuously proliferative

779 as evidenced by the up-regulations of $\mathrm{p} 53 / \mathrm{Rb} / \mathrm{E} 2 \mathrm{~F}$ and $\mathrm{Wnt} / \beta$-catenin signaling, though

780 they only showed a slight increase in cell numbers after $24 \mathrm{~h}$ of pamidronate treatment

781 versus non-treated controls, which suggests some cells unable to differentiate into

782 mature macrophages may have succumbed to FAS-mediated or PARP-1-associated

783 apoptosis.

784 Pamidronate reduced the expressions of the osteoclastogenesis-related proteins,

785 RANKL and cathepsin K in RAW 264.7 cells, indicating it inhibited osteoclast

786 differentiation, which is in-line with the reported disappearance of osteoclasts in

787 bisphosphonate-treated animals (Kameka et al. 2014; Kawata et al. 2004; Mayahara \& 
788 Sasaki 2003) and has implications regarding the effects of pamidronate effects on 789 osteolytic diseases such as including osteoporosis, fibrous dysplasia, Paget's disease, 790 and Gorham's disease (Hammer et al. 2005; Kravets 2018; Saraff et al. 2018), etc. 791 Pamidronate also downregulated the osteoblast differentiation proteins OPG, 792 RUNX2, osterix, and osteocalcin but slightly induced the expressions of bone matrix 793 proteins such as osteopontin, BMP-2, BMP-4, osteonectin, and ALP together with BMP7943 which negatively regulates bone density. These findings may be relevant to the 795 osteoinductive effects of low-dose bisphosphonate reported in chronic periodontitis and 796 after dental implantation (Alqhtani et al. 2017; Ata-Ali et al. 2016; Bhavsar et al. 2016; Khojasteh et al. 2019). However, pamidronate-treated RAW 264.7 cells may negatively regulate cytodifferentiation to osteoblasts in vivo and their abnormal bone production 799 can contribute to the disruption of Haversian system canaliculi, which leads osteocyte 800 death and increases the risk of osteonecrotic infections like BRONJ (Acevedo et al. 801 2015; Favia et al. 2009; Park et al. 2009).

802 Interestingly, pamidronate altered expressions of inflammatory proteins in RAW 803264.7 cells both positively and negatively. The expressions of inflammatory proteins that 804 participate in immediate inflammatory reaction, e.g., TNFa, IL-1, lysozyme, CD68, LL80537 , and $\beta$-defensin-1, $-2,-3$, were markedly reduced, whereas those that participate in 806 delayed inflammatory reaction, e.g., CD3, CD80, Pdcd-1/1, IL-12, and MCP-1, were 807 elevated. The inhibition of immediate inflammatory reaction results the failure of innate 808 immunity, and is relevant to severe necrotic infection of BRONJ involved with reduction 809 of granulation tissue (Burr \& Allen 2009; Carmagnola et al. 2013; Marx \& Tursun 2012; 810 Ziebart et al. 2011). Actually, pamidronate markedly suppressed the expressions of the 
811 angiogenesis-related proteins, HIF-1 $\alpha$, VEGF-A, VERFR2, p-VEGFR2, vWF, CMG2,

812 FGF-1, FGF-2, MMP-2, MMP-10, COX-1, PAI-1, VCAM-1, and PECAM-1 in RAW 264.7

813 cells versus non-treated controls but had relatively little effect on the expressions of the

814 lymphatic vessel-related proteins, VEGF-C, LYVE-1, and FLT-4. These observations

815 suggest that pamidronate-treated RAW 264.7 cells do not participate in immediate

816 inflammatory reactions and vascular capillary production, but that they still provide some

817 support for lymphatic drainage.

818 Pamidronate was found to widely affect the expressions of proteins in different 819 signaling pathways in RAW 264.7 cells. Its global protein expression changes were 820 illustrated in Fig. 8, exhibiting dynamic impacts on epigenetic modification, protein 821 translation, RAS signaling, NFkB signaling, cellular proliferation, protection, 822 differentiation, survival, apoptosis, inflammation, angiogenesis, and osteoclastogenesis.

823 Highly up- and down-regulated proteins for each cellular functions were summarized in 824 Fig. 9. Pamidronate induced marked over- and under-expression of some elective 825 proteins more than $20 \%$ compared to non-treated controls, which may play 826 pathogenetic roles (biomarkers) for cellular differentiation, inflammation, apoptosis, 827 angiogenesis, and osteoclastogenesis in RAW 254.7 cells.

828

\section{Conclusions}

830

Summarizing, pamidronate was found to alter the expressions of many important 832 proteins in RAW 264.7 cells. It upregulated proliferation-related proteins associated with 833 $\mathrm{p} 53 / \mathrm{Rb} / \mathrm{E} 2 \mathrm{~F}$ and $\mathrm{Wnt} / \mathrm{\beta}$-catenin signaling and inactivated epigenetic modification and

834 protein translation. In addition, RAS (cellular growth) and NFkB (cellular stress) 
835 signalings were markedly affected by pamidronate. Pamidronate-treated cells showed 836 that upstream of RAS signaling was stimulated by up-regulation of some growth factors, 837 while downstream of RAS signaling was attenuated by down-regulation of ERK-1 and p838 ERK-1, resulted in reduction of cMyc/MAX/MAD network expression. They also showed 839 suppression of NFkB signaling by downregulating p38 and p-p38 and upregulating 840 mTOR. Consequently, pamidronate affects global protein expression in RAW 264.7 841 cells by downregulating the expressions of immediate inflammation, cellular

842 differentiation, survival, angiogenesis, and osteoclastogenesis-related proteins, but by 843 upregulating PARP-1- and FAS-mediated apoptosis, protection, and proliferation-related 844 proteins. These findings suggest pamidronate has potent anti-inflammatory, anti845 angiogenesis, and anti-osteoporotic effects together with cellular stresses dysregulating 846 RAS signaling, NFkB signaling, apoptosis, and proliferation. The present study explored

847 the global expressions of representative essential proteins $(n=218)$ in pamidronate848 treated RAW 264.7 cells, but some affected proteins were so dynamic and variable that 849 they should be continuously monitored by IP-HPLC, if pamidronate treatment will be 850 prolonged. Finally, we suggest further molecular biologic studies be undertaken on 851 interactions between pamidronate and target proteins.

852

853

854

855

856

857

858

859

860

\section{Acknowledgements}

We express our gratitude to the late Professor Je G. Chi, who encouraged us to perform IP-HPLC and to the late Dr. Soo II Chung who taught us the biological usefulness of HPLC. 
861

862

863

Abelson, A., 2008. A review of Paget's disease of bone with a focus on the efficacy and safety of

864

865

Acevedo, C., Bale, H., Gludovatz, B., Wat, A., Tang, S.Y., Wang, M., Busse, B., Zimmermann, E.A., 866 Schaible, E., Allen, M.R., Burr, D.B., and Ritchie, R.O., 2015. Alendronate treatment alters bone tissues 867 at multiple structural levels in healthy canine cortical bone. Bone, 81(352-363

868

Akram, Z., Abduljabbar, T., Kellesarian, S.V., Abu Hassan, M.I., Javed, F., and Vohra, F., 2017. Efficacy 870 of bisphosphonate as an adjunct to nonsurgical periodontal therapy in the management of periodontal

871 disease: a systematic review. Br J Clin Pharmacol, 83(3):444-454

872

Alqhtani, N.R., Logan, N.J., Meghji, S., Leeson, R., and Brett, P.M., 2017. Low dose effect of 874 bisphosphonates on hMSCs osteogenic response to titanium surface in vitro. Bone reports, 6(64-69

875

876

Ariza Jimenez, A.B., Nunez Cuadros, E., Galindo Zavala, R., Nunez Caro, L., Diaz-Cordobes Rego, 877 G., and Urda Cardona, A., 2018. Recurrent multifocal osteomyelitis in children: Experience in a tertiary

878 care center. Reumatologia clinica, 14(6):334-338

879

Ata-Ali, J., Ata-Ali, F., Penarrocha-Oltra, D., and Galindo-Moreno, P., 2016. What is the impact of 881 bisphosphonate therapy upon dental implant survival? A systematic review and meta-analysis. Clinical 882 oral implants research, 27(2):e38-46

883

Bhavsar, N.V., Trivedi, S.R., Dulani, K., Brahmbhatt, N., Shah, S., and Chaudhri, D., 2016. Clinical and 885 radiographic evaluation of effect of risedronate $5 \mathrm{mg}$ as an adjunct to treatment of chronic periodontitis 886 in postmenopausal women (12-month study). Osteoporos Int, 27(8):2611-2619

887

Burr, D.B., and Allen, M.R., 2009. Mandibular necrosis in beagle dogs treated with bisphosphonates. 889 Orthodontics \& craniofacial research, 12(3):221-228

890

891

Carmagnola, D., Canciani, E., Sozzi, D., Biglioli, F., Moneghini, L., and Dellavia, C., 2013. Histological 892 findings on jaw osteonecrosis associated with bisphosphonates (BONJ) or with radiotherapy (ORN) in 893 humans. Acta odontologica Scandinavica, 71(6):1410-1417 
894

895 Cecchini, M.G., Felix, R., Fleisch, H., and Cooper, P.H., 1987. Effect of bisphosphonates on proliferation 896 and viability of mouse bone marrow-derived macrophages. J Bone Miner Res, 2(2):135-142

897

Chen, C., Xia, M., Wu, L., Zhou, C., and Wang, F., 2012. Modeling the interaction of seven 899 bisphosphonates with the hydroxyapatite(100) face. Journal of molecular modeling, 18(9):4007-4012

900

901

902

Chen, Z., Cheng, L., and Feng, G., 2018. Bone inflammation and chronic recurrent multifocal

903

904

Chevreau, M., Romand, X., Gaudin, P., Juvin, R., and Baillet, A., 2017. Bisphosphonates for treatment 905 of Complex Regional Pain Syndrome type 1: A systematic literature review and meta-analysis of 906 randomized controlled trials versus placebo. Joint Bone Spine, 84(4):393-399

907

Chirappapha, P., Kitudomrat, S., Thongjood, T., and Aroonroch, R., 2017. Bisphosphonate-related 909 osteonecrosis of jaws in advanced stage breast cancer was detected from bone scan: a case report.

910 Gland surgery, 6(1):93-100

911

Choi, W.S., Lee, J.I., Yoon, H.J., Min, C.K., and Lee, S.H., 2017. Medication-related osteonecrosis of the jaw: a preliminary retrospective study of 130 patients with multiple myeloma. Maxillofacial plastic and reconstructive surgery, 39(1):1-7

915

Clarke, N.J., Tomlinson, A.J., Ohyagi, Y., Younkin, S., and Naylor, S., 1998. Detection and quantitation 917 of cellularly derived amyloid beta peptides by immunoprecipitation-HPLC-MS. FEBS letters, 430(3):419918423

919

920

Ebetino, F.H., Hogan, A.M., Sun, S., Tsoumpra, M.K., Duan, X., Triffitt, J.T., Kwaasi, A.A., Dunford, J.E., Barnett, B.L., Oppermann, U., Lundy, M.W., Boyde, A., Kashemirov, B.A., McKenna, C.E., and Russell, R.G., 2011. The relationship between the chemistry and biological activity of the 923 bisphosphonates. Bone, 49(1):20-33

924

925

Endo, Y., Nakamura, M., Kikuchi, T., Shinoda, H., Takeda, Y., Nitta, Y., and Kumagai, K., 1993. 926 Aminoalkylbisphosphonates, potent inhibitors of bone resorption, induce a prolonged stimulation of 
927 histamine synthesis and increase macrophages, granulocytes, and osteoclasts in vivo. Calcif Tissue Int, 928 52(3):248-254

929

930 Escudero, N.D., and Mandalunis, P.M., 2012. Influence of bisphosphonate treatment on medullary 931 macrophages and osteoclasts: an experimental study. Bone marrow research, 2012(1):526236-526243

932

933

Favia, G., Pilolli, G.P., and Maiorano, E., 2009. Histologic and histomorphometric features of

934 bisphosphonate-related osteonecrosis of the jaws: an analysis of 31 cases with confocal laser scanning 935 microscopy. Bone, 45(3):406-413

936

Fernandez, D., Vega, D., and Goeta, A., 2002. The calcium-binding properties of pamidronate, a bone938 resorption inhibitor. Acta crystallographica Section C, Crystal structure communications, 58(Pt 939 10):m494-497

940

Guimaraes, E.P., Pedreira, F.R., Jham, B.C., de Carli, M.L., Pereira, A.A., and Hanemann, J.A., 2013.

942 Clinical management of suppurative osteomyelitis, bisphosphonate-related osteonecrosis, and 943 osteoradionecrosis: report of three cases and review of the literature. Case reports in dentistry, 944 2013(402096

945

Hammer, F., Kenn, W., Wesselmann, U., Hofbauer, L.C., Delling, G., Allolio, B., and Arlt, W., 2005.

947 Gorham-Stout disease--stabilization during bisphosphonate treatment. J Bone Miner Res, 20(2):350948353

Hansen, P.J., Knitschke, M., Draenert, F.G., Irle, S., and Neff, A., 2012. Incidence of bisphosphonate951 related osteonecrosis of the jaws (BRONJ) in patients taking bisphosphonates for osteoporosis 952 treatment-a grossly underestimated risk? Clin Oral Investig,

953

Henneman, L., van Cruchten, A.G., Kulik, W., and Waterham, H.R., 2011. Inhibition of the isoprenoid 955 biosynthesis pathway; detection of intermediates by UPLC-MS/MS. Biochimica et biophysica acta, 956 1811(4):227-233

957

958

Hoefert, S., Hoefert, C.S., Albert, M., Munz, A., Grimm, M., Northoff, H., Reinert, S., and Alexander, 959 D., 2015. Zoledronate but not denosumab suppresses macrophagic differentiation of THP-1 cells. An 
960 aetiologic model of bisphosphonate-related osteonecrosis of the jaw (BRONJ). Clin Oral Investig, 961 19(6):1307-1318

962

963 Hoefert, S., Sade Hoefert, C., Munz, A., Northoff, H., Yuan, A., Reichenmiller, K., Reinert, S., and

964 Grimm, M., 2016a. Altered macrophagic THP-1 cell phagocytosis and migration in bisphosphonate965 related osteonecrosis of the jaw (BRONJ). Clin Oral Investig, 20(5):1043-1054

966

967

Hoefert, S., Sade Hoefert, C., Munz, A., Schmitz, I., Grimm, M., Yuan, A., Northoff, H., Reinert, S., 968 and Alexander, D., 2016b. Effect of bisphosphonates on macrophagic THP-1 cell survival in 969 bisphosphonate-related osteonecrosis of the jaw (BRONJ). Oral surgery, oral medicine, oral pathology 970 and oral radiology, 121(3):222-232

971

972

Hong, J.W., Nam, W., Cha, I.H., Chung, S.W., Choi, H.S., Kim, K.M., Kim, K.J., Rhee, Y., and Lim, S.K., 973 2010. Oral bisphosphonate-related osteonecrosis of the jaw: the first report in Asia. Osteoporos Int, 974 21(5):847-853

975

Iguchi, K., Tatsuda, Y., Usui, S., and Hirano, K., 2010. Pamidronate inhibits antiapoptotic bcl-2 977 expression through inhibition of the mevalonate pathway in prostate cancer PC-3 cells. Eur J Pharmacol, 978 641(1):35-40

979

980

Ito, M., Amizuka, N., Nakajima, T., and Ozawa, H., 2001. Bisphosphonate acts on osteoclasts 981 independent of ruffled borders in osteosclerotic (oc/oc) mice. Bone, 28(6):609-616

982

Jayasena, A., Atapattu, N., and Lekamwasam, S., 2015. Treatment of glucocorticoid-induced low bone 984 mineral density in children: a systematic review. International journal of rheumatic diseases, 18(3):287985 293

986

987

Jeong, H.G., Hwang, J.J., Lee, J.H., Kim, Y.H., Na, J.Y., and Han, S.S., 2017. Risk factors of 988 osteonecrosis of the jaw after tooth extraction in osteoporotic patients on oral bisphosphonates. 989 Imaging science in dentistry, 47(1):45-50

990

991

Kaiser, T., Teufel, I., Geiger, K., Vater, Y., Aicher, W.K., Klein, G., and Fehm, T., 2013. Bisphosphonates 992 modulate vital functions of human osteoblasts and affect their interactions with breast cancer cells. 
993

994

995

996

997

998

999

1000

1001

1002

1003

1004

1005

1006

1007

1008

1009

1010

1011

1012

1013

1014

1015

1016

1017

1018

1019

1020

1021

1022

1023

1024

1025

Breast cancer research and treatment, 140(1):35-48

Kameka, A.M., Haddadi, S., Jamaldeen, F.J., Moinul, P., He, X.T., Nawazdeen, F.H., Bonfield, S., Sharif, S., van Rooijen, N., and Abdul-Careem, M.F., 2014. Clodronate treatment significantly depletes macrophages in chickens. Canadian journal of veterinary research = Revue canadienne de recherche veterinaire, 78(4):274-282

Kamel, A.A., Geronikaki, A., and Abdou, W.M., 2012. Inhibitory effect of novel S,N-bisphosphonates on some carcinoma cell lines, osteoarthritis, and chronic inflammation. European journal of medicinal chemistry, 51(239-249

Kawata, T., Tenjou, K., Tokimasa, C., Fujita, T., Kaku, M., Matsuki, A., Kohno, S., Tsutsui, K., Ohtani, J., Motokawa, M., Shigekawa, M., Tohma, Y., and Tanne, K., 2004. Effect of alendronate on osteoclast differentiation and bone volume in transplanted bone. Experimental animals / Japanese Association for Laboratory Animal Science, 53(1):47-51

Khojasteh, A., Dehghan, M.M., and Nazeman, P., 2019. Immediate implant placement following 1year treatment with oral versus intravenous bisphosphonates: a histomorphometric canine study on peri-implant bone. Clin Oral Investig, 23(4):1803-1809

Kim, M.K., Hong, J.R., Kim, S.G., and Lee, S.K., 2015. Fatal Progression of Gorham Disease: A Case Report and Review of the Literature. J Oral Maxillofac Surg, 73(12):2352-2360

Kim, M.K., Yoon, C.S., G., K.S., Park, Y.W., Lee, S.S., and Lee, S.K., 2019. Effects of 4-Hexylresorcinol on Protein Expressions in RAW 264.7 Cells as Determined by Immunoprecipitation High Performance Liquid Chromatography. Scientific reports, 9(3379-3394

Kim, S.M., Eo, M.Y., Cho, Y.J., Kim, Y.S., and Lee, S.K., 2017a. Wound healing protein profiles in the postoperative exudate of bisphosphonate-related osteonecrosis of mandible. Eur Arch Otorhinolaryngol, 274(9):3485-3495

Kim, S.M., Eo, M.Y., Cho, Y.J., Kim, Y.S., and Lee, S.K., 2017b. Differential protein expression in the secretory fluids of maxillary sinusitis and maxillary retention cyst. Eur Arch Otorhinolaryngol, 274(1):215- 
1026222

1027

1028 Kim, S.M., Eo, M.Y., Kim, Y.S., and Lee, S.K., 2017c. Histochemical observation of bony reversal lines 1029 in bisphosphonate-related osteonecrosis of the jaw. Oral surgery, oral medicine, oral pathology and 1030 oral radiology, 123(2):220-228

1031

1032

Kim, S.M., Jeong, D., Kim, M.K., Lee, S.S., and Lee, S.K., 2017d. Two different protein expression 1033 profiles of oral squamous cell carcinoma analyzed by immunoprecipitation high-performance liquid 1034 chromatography. World journal of surgical oncology, 15(1):151

1035

Kim, S.M., Eo, M.Y., Cho, Y.J., Kim, Y.S., and Lee, S.K., 2018. Immunoprecipitation high performance 1037 liquid chromatographic analysis of healing process in chronic suppurative osteomyelitis of the jaw. $J$ 1038 Craniomaxillofac Surg, 46(1):119-127

1039

Kim, Y.S., and Lee, S.K., 2015. IP-HPLC Analysis of Human Salivary Protein Complexes. Korean Journal 1041 of Oral and Maxillofacial Pathology, 39(5):615-622

1042

Kravets, I., 2018. Paget's Disease of Bone: Diagnosis and Treatment. Am J Med, 131(11):1298-1303

1044

Kun-Darbois, J.D., Libouban, H., Mabilleau, G., Pascaretti-Grizon, F., and Chappard, D., 2018. Bone 1046 mineralization and vascularization in bisphosphonate-related osteonecrosis of the jaw: an experimental study in the rat. Clin Oral Investig, 22(9):2997-3006

1048

Lee, S.K., 2013. Ultrastructural Changes of Bone in Bisphosphonate-related Osteonecrosis of Jaws. Kor 1050 J Oral Maxillofac Pathol, 37(5):183-192

1051

Luo, L., Shen, L., Sun, F., and Ma, Z., 2013. Immunoprecipitation coupled with HPLC-MS/MS to discover 1053 the aromatase ligands from Glycyrrhiza uralensis. Food chemistry, 138(1):315-320

1054 
1058

1059

1060

1061

1062

1063

1064

1065

1066

1067

1068

1069

1070

1071

1072

1073

1074

1075

1076

1077

1078

1079

1080

1081

1082

1083

1084

1085

1086

1087

1088

1089

1090

Marx, R.E., Sawatari, Y., Fortin, M., and Broumand, V., 2005. Bisphosphonate-induced exposed bone (osteonecrosis/osteopetrosis) of the jaws: risk factors, recognition, prevention, and treatment. J Oral Maxillofac Surg, 63(11):1567-1575

Marx, R.E., and Tursun, R., 2012. Suppurative osteomyelitis, bisphosphonate induced osteonecrosis, osteoradionecrosis: a blinded histopathologic comparison and its implications for the mechanism of each disease. Int J Oral Maxillofac Surg, 41(3):283-289

Mayahara, M., and Sasaki, T., 2003. Cellular mechanism of inhibition of osteoclastic resorption of bone and calcified cartilage by long-term pamidronate administration in ovariectomized mature rats. The anatomical record Part A, Discoveries in molecular, cellular, and evolutionary biology, 274(1):817-826

Mian, M., Benetti, D., Aloisi, R., Rosini, S., and Fantozzi, R., 1994. Effects of bisphosphonate derivatives on macrophage function. Pharmacology, 49(5):336-342

Miyazaki, T., Miyauchi, S., Anada, T., Imaizumi, H., and Suzuki, O., 2011. Evaluation of osteoclastic resorption activity using calcium phosphate coating combined with labeled polyanion. Anal Biochem, 410(1):7-12

Nishida, S., Fujii, Y., Yoshioka, S., Kikuichi, S., Tsubaki, M., and Irimajiri, K., 2003. A new bisphosphonate, YM529 induces apoptosis in HL60 cells by decreasing phosphorylation of single survival signal ERK. Life Sci, 73(21):2655-2664

Ohlrich, E.J., Coates, D.E., Cullinan, M.P., Milne, T.J., Zafar, S., Zhao, Y., Duncan, W.D., and Seymour, G.J., 2016. The bisphosphonate zoledronic acid regulates key angiogenesis-related genes in primary human gingival fibroblasts. Arch Oral Biol, 63(7-14

Park, J.M., Lee, S.W., Kim, J.H., Park, Y.W., Song, J.Y., Lee, S.S., Kim, Y.S., and Lee, S.K., 2009. Recurrent Osteomyelitis Caused by Bisphosphonate Intake Showed Abnormal Osteophytes Lack of Harversian System. Kor J Oral Maxillofac Pathol, 33(4):181-190

Polyzos, S.A., Anastasilakis, A.D., Makras, P., and Terpos, E., 2011. Paget's disease of bone and 
1091 1092524

1093

1094

1095

1096

1097

1098

1099

1100

1101

1102

1103

1104

1105

1106

1107

1108

1109

1110

1111

1112

1113

1114

1115

1116

1117

1118

1119

1120

1121

1122

calcium homeostasis: focus on bisphosphonate treatment. Exp Clin Endocrinol Diabetes, 119(9):519-

Ribatti, D., Maruotti, N., Nico, B., Longo, V., Mangieri, D., Vacca, A., and Cantatore, F.P., 2008. Clodronate inhibits angiogenesis in vitro and in vivo. Oncology reports, 19(5):1109-1112

Ruggiero, S.L., Mehrotra, B., Rosenberg, T.J., and Engroff, S.L., 2004. Osteonecrosis of the jaws associated with the use of bisphosphonates: a review of 63 cases. J Oral Maxillofac Surg, 62(5):527-534

Sansom, L.N., Necciari, J., and Thiercelin, J.F., 1995. Human pharmacokinetics of tiludronate. Bone, 17(5 Suppl):479S-483S

Saraff, V., Sahota, J., Crabtree, N., Sakka, S., Shaw, N.J., and Hogler, W., 2018. Efficacy and treatment costs of zoledronate versus pamidronate in paediatric osteoporosis. Arch Dis Child, 103(1):92-94

Sarasquete, M.E., Gonzalez, M., San Miguel, J.F., and Garcia-Sanz, R., 2009. Bisphosphonate-related osteonecrosis: genetic and acquired risk factors. Oral Dis, 15(6):382-387

Sato, M., Grasser, W., Endo, N., Akins, R., Simmons, H., Thompson, D.D., Golub, E., and Rodan, G.A., 1991. Bisphosphonate action. Alendronate localization in rat bone and effects on osteoclast ultrastructure. J Clin Invest, 88(6):2095-2105

Seo, M.H., Myoung, H., Lee, J.H., Kim, S.M., and Lee, S.K., 2019. Changes in oncogenic protein levels in peri-implant oral malignancy: a case report. Maxillofacial plastic and reconstructive surgery, 41(1):46

Sharma, D., Hamlet, S.M., Petcu, E.B., and Ivanovski, S., 2016. The effect of bisphosphonates on the endothelial differentiation of mesenchymal stem cells. Scientific reports, $\mathbf{6}(20580$

Singer, F.R., Bone, H.G., 3rd, Hosking, D.J., Lyles, K.W., Murad, M.H., Reid, I.R., and Siris, E.S., 2014. Paget's disease of bone: an endocrine society clinical practice guideline. J Clin Endocrinol Metab, 99(12):4408-4422

PeerJ reviewing PDF | (2020:01:45256:2:0:NEW 18 Apr 2020) 
1123 Stefanucci, A., Marrone, A., and Agamennone, M., 2015. Investigation of the N-BP Binding at FPPS

1124 by Combined Computational Approaches. Med Chem, 11(5):417-431

1125

1126 Tatsuda, Y., Iguchi, K., Usui, S., Suzui, M., and Hirano, K., 2010. Protein kinase C is inhibited by

1127 bisphosphonates in prostate cancer PC-3 cells. Eur J Pharmacol, 627(1-3):348-353

1128

1129

Wat, W.Z., 2014. Current perspectives on bisphosphonate treatment in Paget's disease of bone. Ther

1130 Clin Risk Manag, 10(977-983

1131

Yoon, C.S., Kim, M.K., Kim, Y.S., and Lee, S.K., 2018a. In vivo protein expression changes in mouse livers treated with dialyzed coffee extract as determined by IP-HPLC. Maxillofacial plastic and reconstructive surgery, $\mathbf{4 0 ( 1 ) : 4 4}$

1135

1136

Yoon, C.S., Kim, M.K., Kim, Y.S., and Lee, S.K., 2018b. In vitro protein expression changes in RAW 264.7 cells and HUVECs treated with dialyzed coffee extract by immunoprecipitation high performance liquid chromatography. Scientific reports, 8(1):13841

1139

Zhang, Q., Atsuta, I., Liu, S., Chen, C., Shi, S., and Le, A.D., 2013. IL-17-Mediated M1/M2 Macrophage Alteration Contributes to Pathogenesis of Bisphosphonate-Related Osteonecrosis of the Jaws. Clin Cancer Res, 19(12):3176-3188

1143

Zhang, X., Han, J., Man, K., Li, X., Du, J., Chu, E.S., Go, M.Y., Sung, J.J., and Yu, J., 2016. CXC chemokine receptor 3 promotes steatohepatitis in mice through mediating inflammatory cytokines, macrophages and autophagy. J Hepatol, 64(1):160-170 


\section{Figure 1}

In situ proliferation assayof RAW 264.7 cells

Figure 1. In situ proliferation assay of RAW 264.7 cells. Increases in cell numbers were determined by counting on Petri dishes (A-F), and proliferation indices (\%) were calculated by expressing cell growths (final-initial cell counts) as percentages of initial cells counts. Pamidronate-treated (6.5 $\mu \mathrm{M}$ ) RAW 264.7 cells had a slightly higher mean proliferation index $(73.1 \pm 2.32 \%$ at $24 \mathrm{~h}$ and $74.7 \pm 2.8 \%$ at $48 \mathrm{~h})$ than nontreated controls $(69.9 \pm 2.46 \%)(G)$.
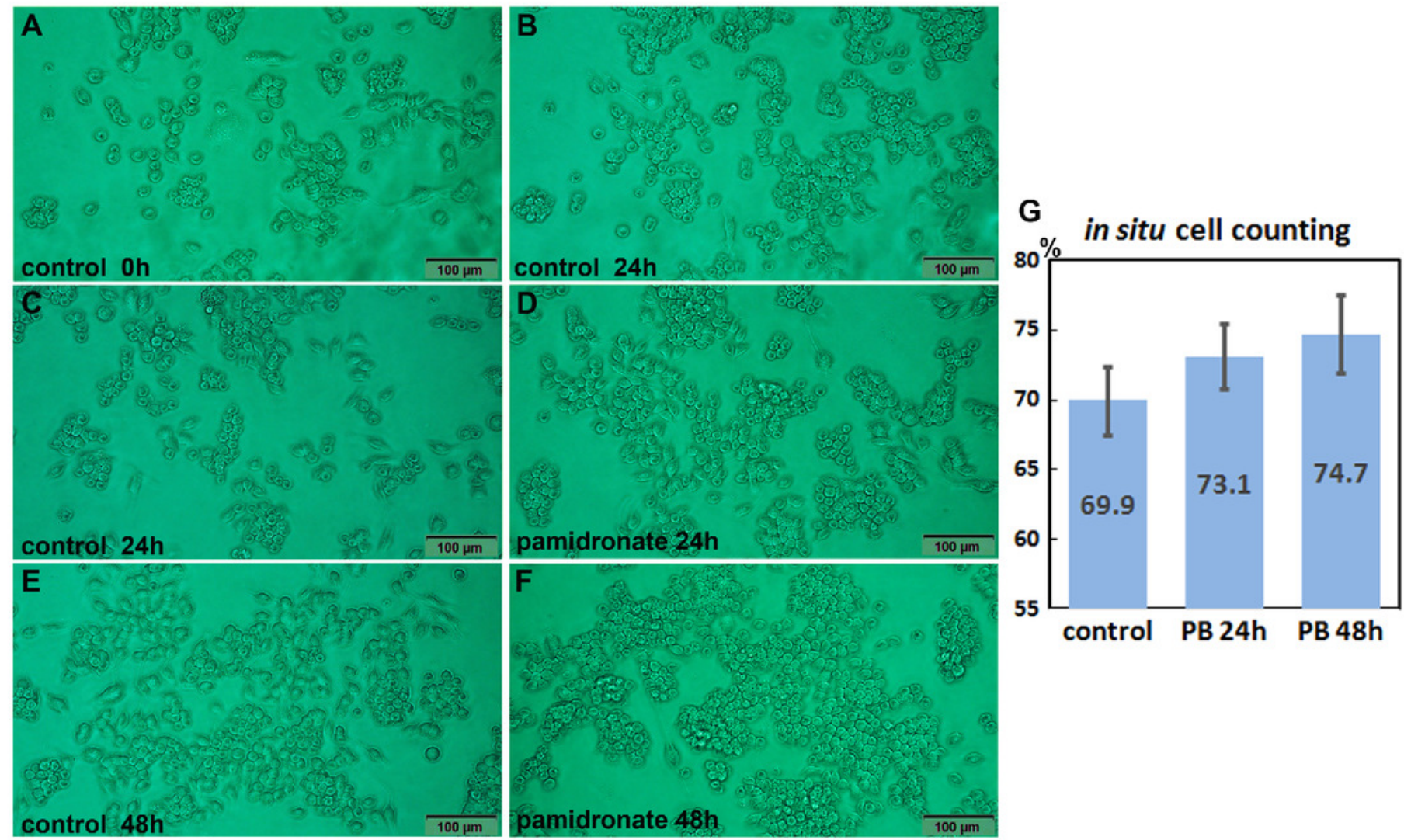


\section{Figure 2}

Expressions ofproliferation-related proteins, cMyc/MAX/MAD network proteins,p53/Rb/E2F signaling proteins, and Wnt/ $\beta$-catenin signaling proteins

Figure 2. Expressions of proliferation-related proteins ( $A$ and $B$ ), cMyc/MAX/MAD network proteins ( $C$ or $D)$, p53/Rb/E2F signaling proteins ( $E$ and $F$ ), and Wnt/ $\beta$-catenin signaling proteins $(F$ or $H$ ) in pamidronatetreated RAW 264.7 cells as determined by IP-HPLC. Line graphs, A, C, E, and G show protein expressional changes on the same scale (\%) versus culture time $(12,24$, or 48 hours), whereas the star plots $(B, D, F$, and $\mathrm{H}$ ) showed the differential expression levels of proteins after 12,24 , or 48 hours of treatment on appropriate scales (\%). Standard error (s). 

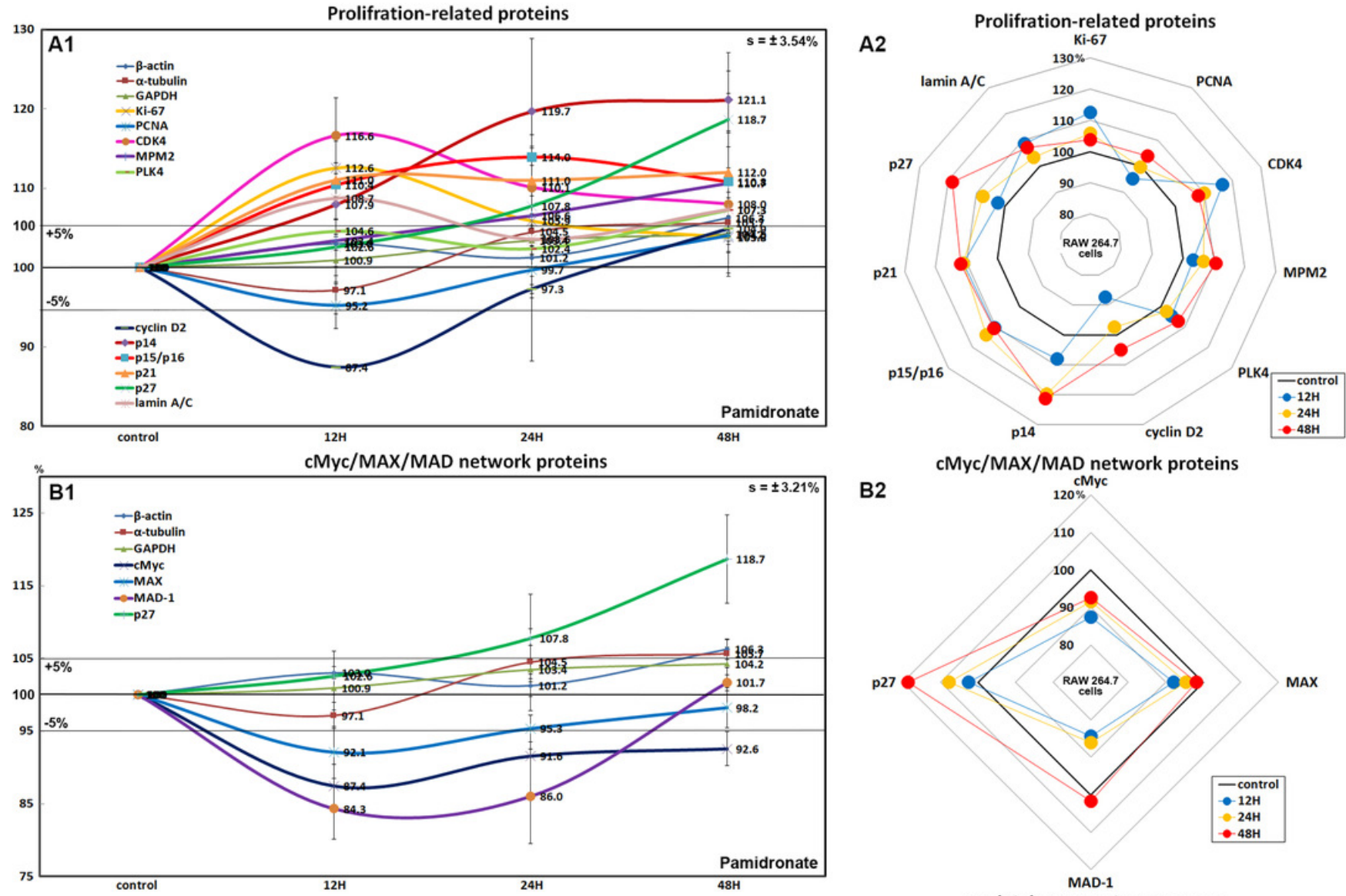

B2

$\mathrm{cMyc/MAX/MAD} \mathrm{network} \mathrm{proteins}$
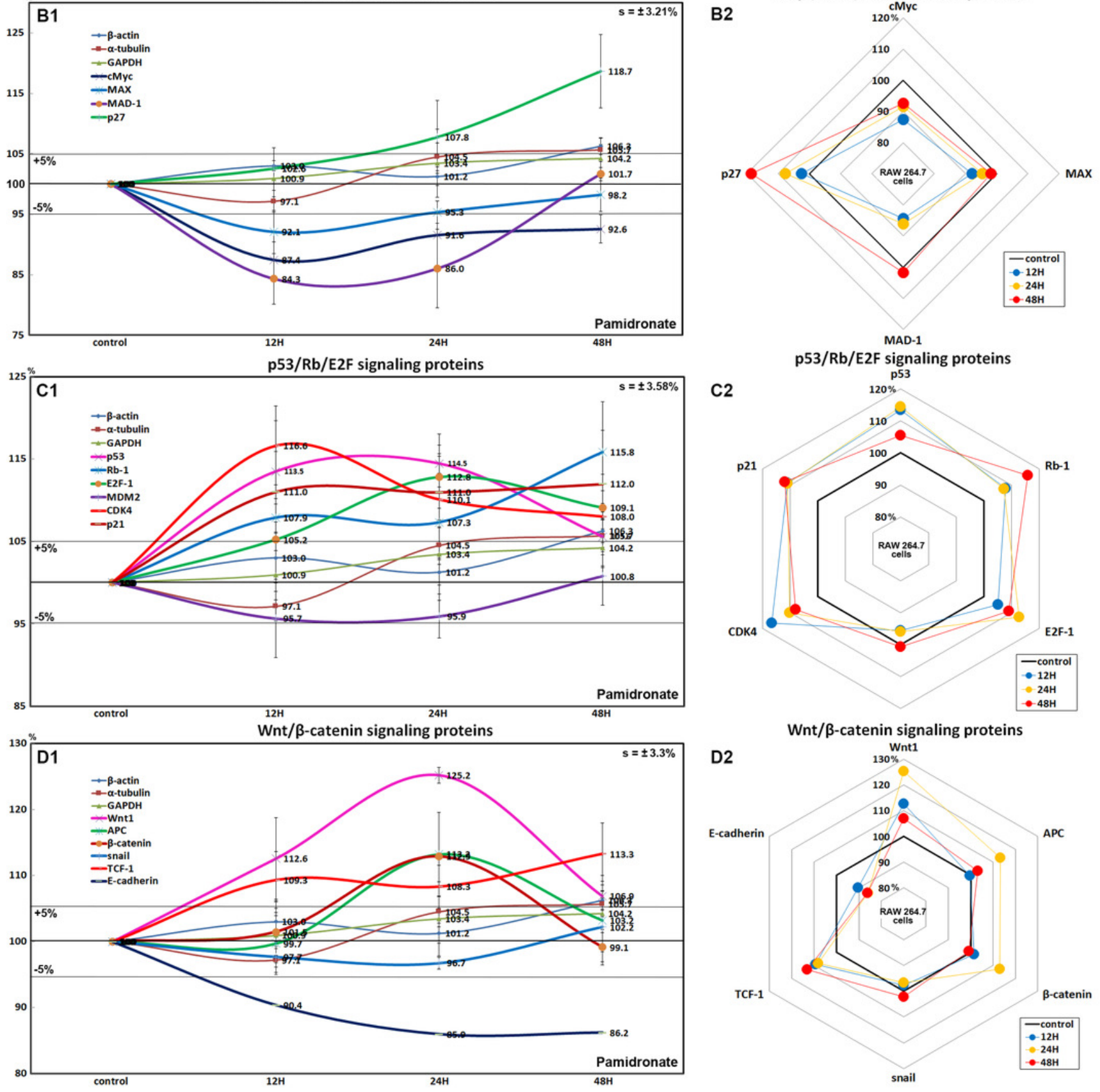

PeerJ reviewing PDF | (2020:01:45256:2:0:NEW 18 Apr 2020) 


\section{Figure 3}

Expressions ofepigenetic modification-related proteins, protein translationrelatedproteins, growth factors, and RAS signaling proteins

Figure 3. Expressions of epigenetic modification-related proteins ( $A$ and $B$ ), protein translation-related proteins ( $C$ or $D$ ), growth factors ( $E$ and $F$ ), and RAS signaling proteins ( $G$ or H) in pamidronate-treated RAW 264.7 cells as determined by IP-HPLC. Line graphs, A, C, E, and $G$ show protein expressional changes on the same scale (\%) versus culture time $(12,24$, or 48 hours), whereas the star plots (B, D, F, and H) showed the differential expression levels of proteins after 12,24 , or 48 hours of treatment on appropriate scales (\%). Standard error (s). 

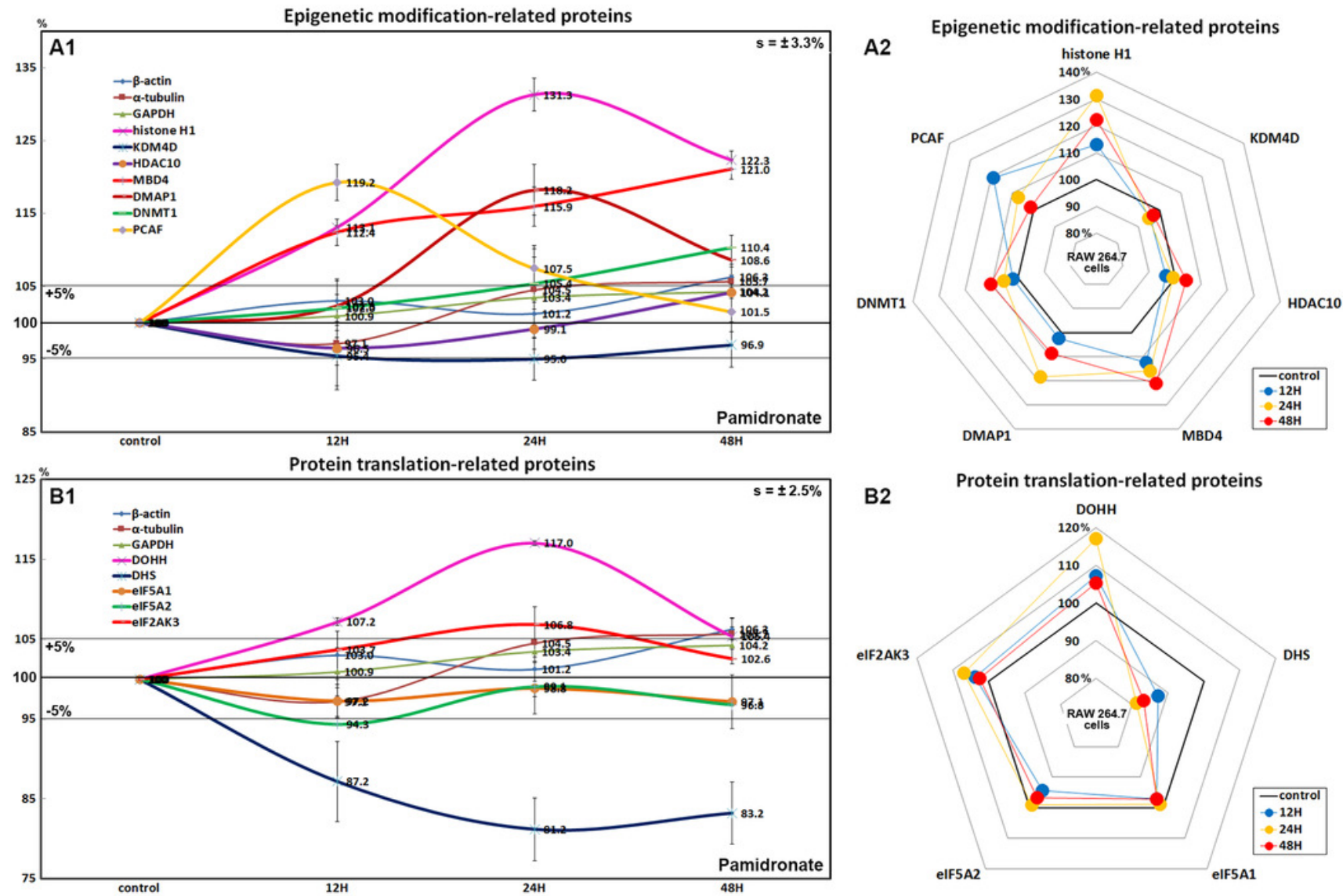

B2

Protein translation-related proteins
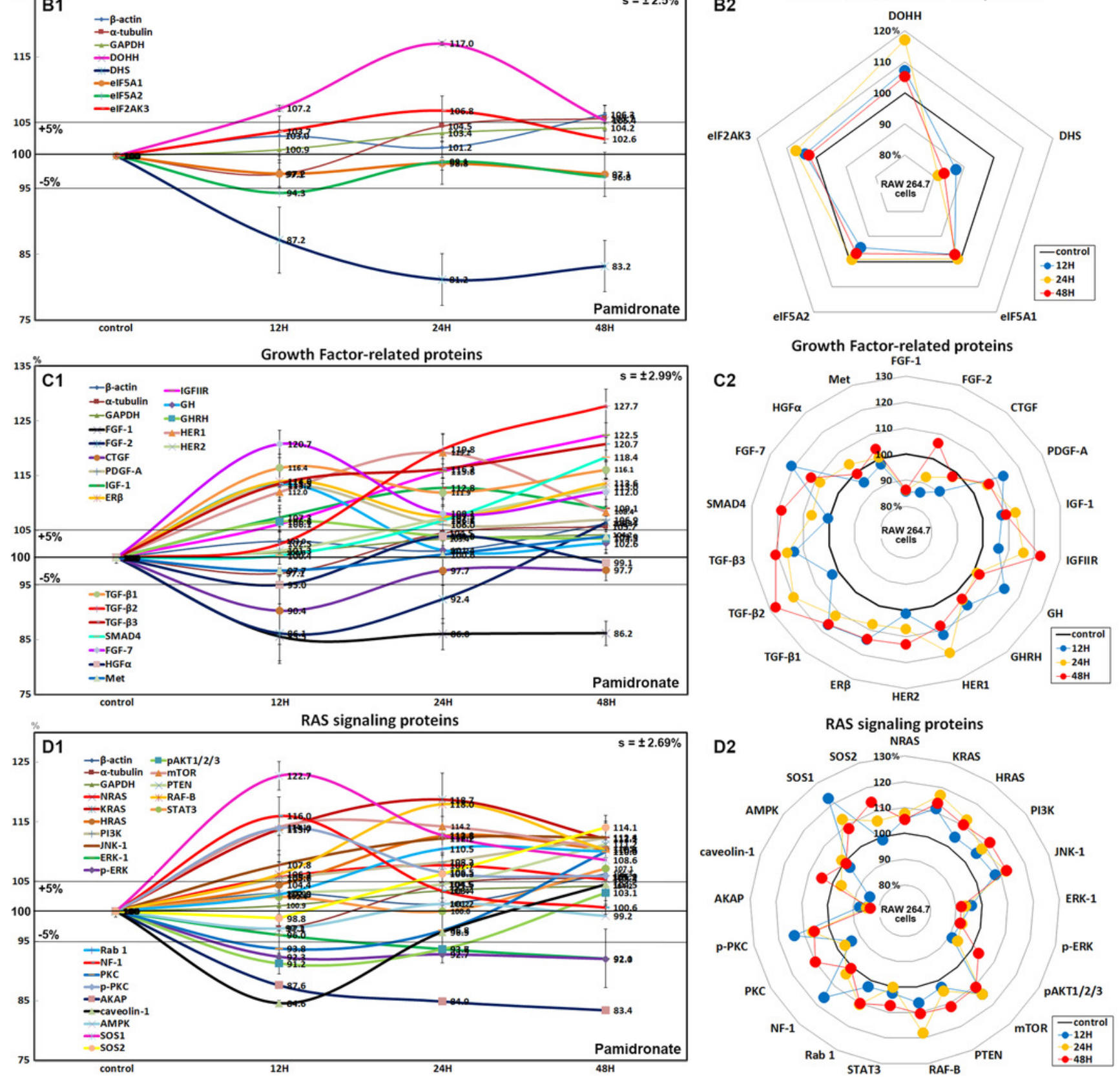


\section{Figure 4}

Expressions of NFkBsignaling proteins, inflammatory proteins were upregulated,and inflammatory proteins downregulated

Figure 4. Expressions of NFkB signaling proteins (A and B), inflammatory proteins were upregulated (C or D), and inflammatory proteins downregulated $(E$ and $F$ ) in pamidronate treated RAW 264.7 cells as determined by IP-HPLC. Line graphs, A, C, and E show protein expressional changes on the same scale (\%) versus culture time $(12,24$, or 48 hours), whereas the star plots (B, D, and F) showed the differential expression levels of proteins after 12,24 , or 48 hours of treatment on appropriate scales (\%). Standard error (s). 

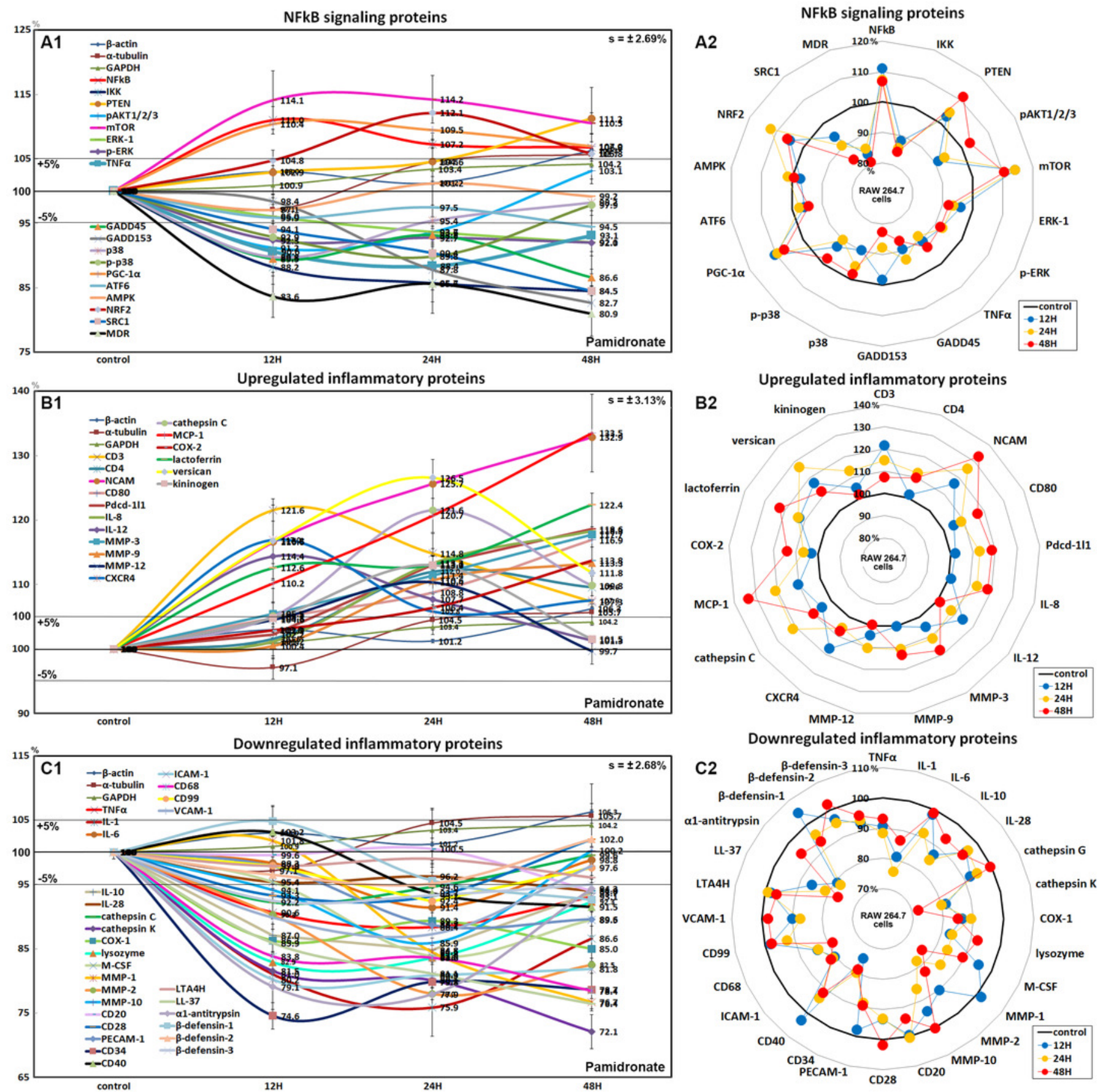


\section{Figure 5}

Expressions ofp53-mediated apoptosis-related proteins, FAS-mediated apoptosisrelatedproteins, and cell survival-related proteins

Figure 5. Expressions of p53-mediated apoptosis-related proteins (A and B), FAS-mediated apoptosis-related proteins ( $C$ or $D$ ), and cell survival-related proteins ( $E$ and $F$ ) in RAW 264.7 cells treated with pamidronate for different times as determined by IP-HPLC. Line graphs, A, C, and E show protein expressional changes on the same scale $(\%)$ versus culture time $(12,24$, or 48 hours), whereas the star plots (B, $D$, and $F)$ showed the differential expression levels of proteins after 12,24 , or 48 hours of treatment on appropriate scales (\%). Standard error (s). 

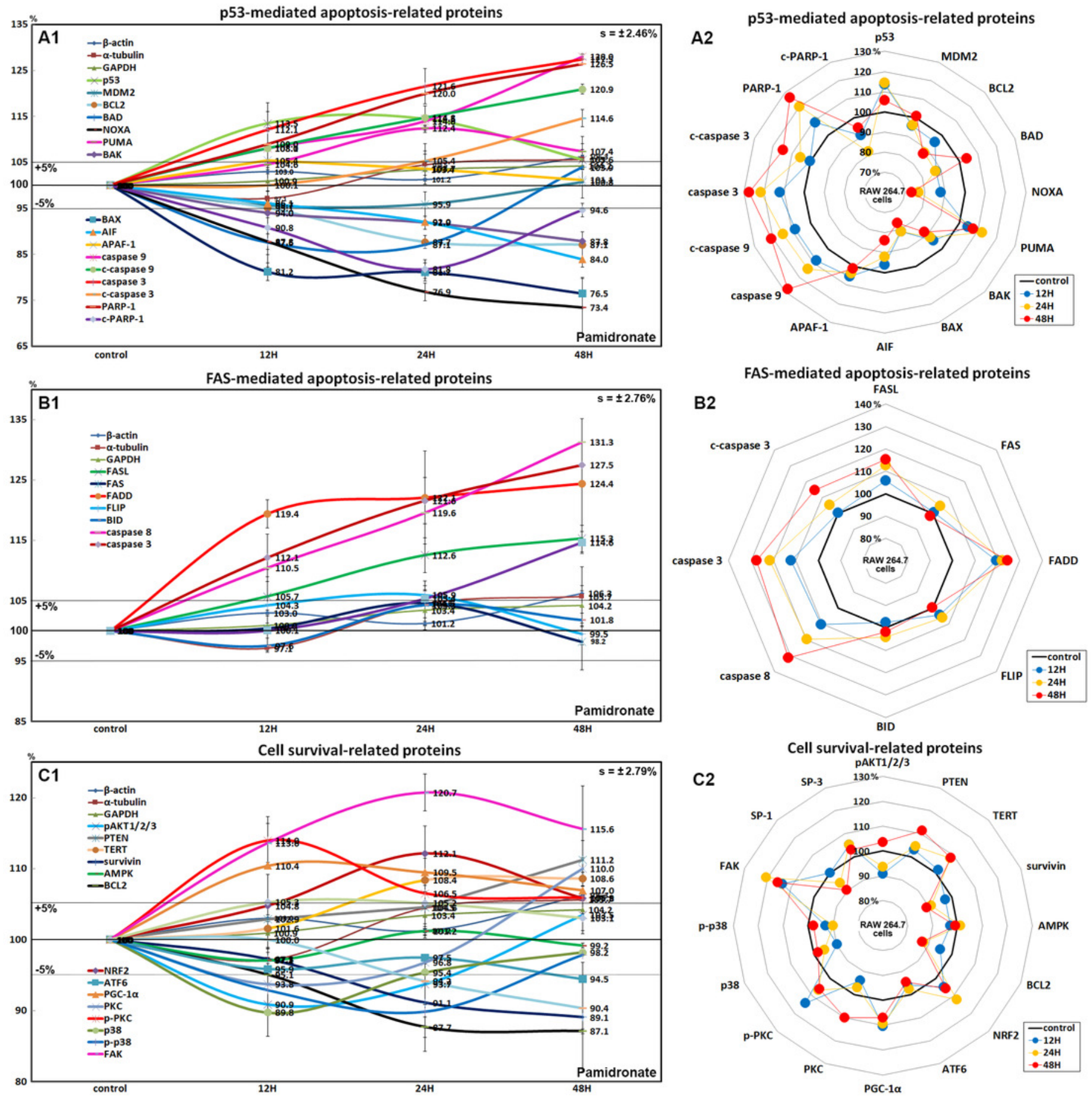


\section{Figure 6}

Expressions of cellprotection-related proteins, differentiation-related proteins, and oncogenesis-related proteins

Figure 6. Expressions of cell protection-related proteins (A and B), differentiation-related proteins (C or D), and oncogenesis-related proteins (E and F) in pamidronate-treated RAW 264.7 cells as determined by IPHPLC. Line graphs, A, C, and E show protein expressional changes on the same scale (\%) versus culture time $(12,24$, or 48 hours), whereas the star plots (B, D, and F) showed the differential expression levels of proteins after 12,24 , or 48 hours of treatment on appropriate scales (\%). Standard error (s). 

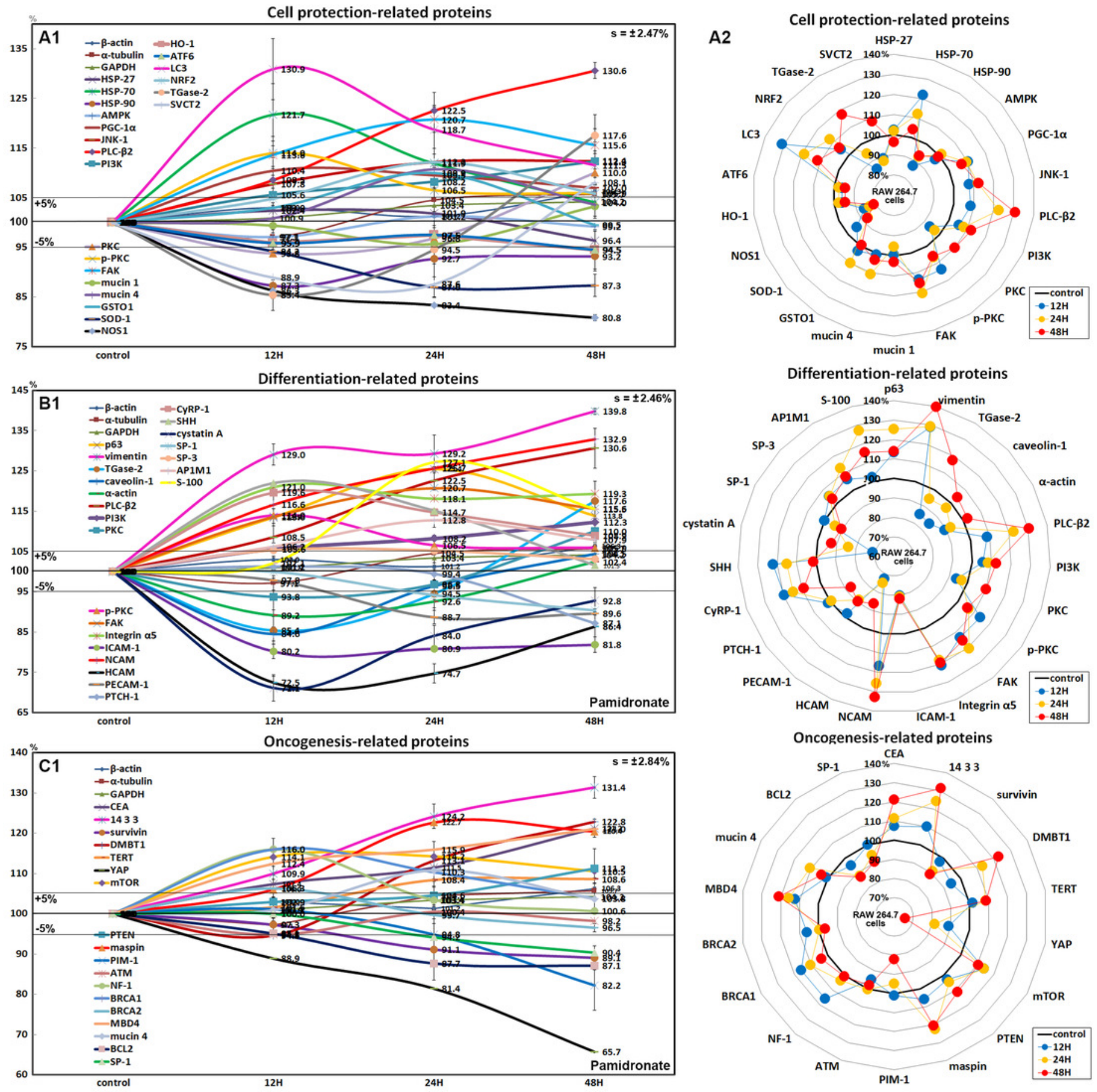
Figure 7

\section{Expressions ofangiogenesis-related proteins and of osteogenesis-related proteins}

Figure 7. Expressions of angiogenesis-related proteins ( $A$ and $B$ ) and of osteogenesis-related proteins ( $C$ or D) in pamidronate-treated RAW 264.7 cells as determined by IP-HPLC. Line graphs, A and C show protein expressional changes on the same scale (\%) versus culture time $(12,24$, or 48 hours), whereas the star plots (B and D) showed the differential expression levels of proteins after 12, 24, or 48 hours of treatment on appropriate scales (\%). Standard error (s).
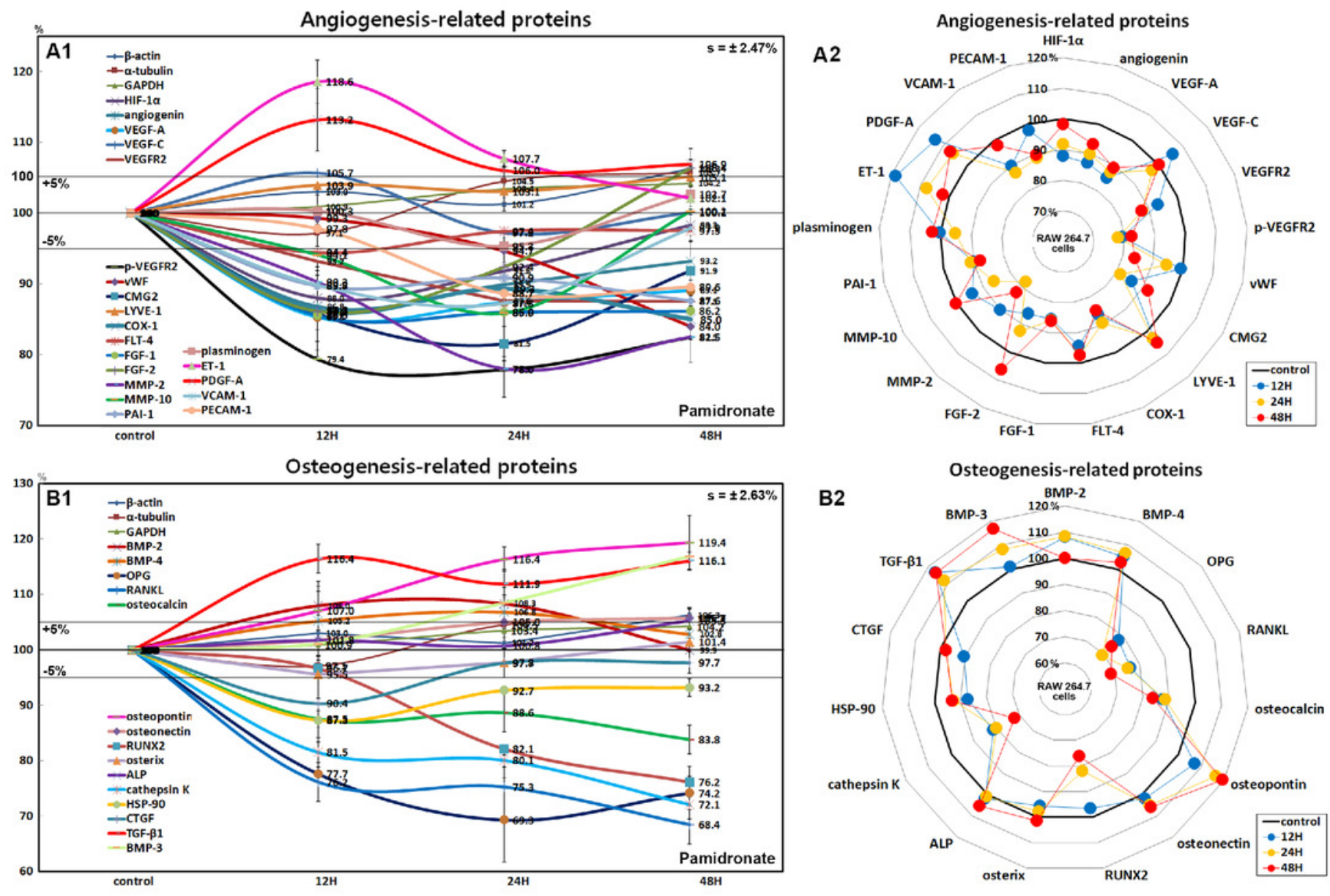


\section{Figure 8}

\section{Star plot of global protein expression inpamidronate-treated RAW 264.7 cells}

Figure 8. Star plot of global protein expression in pamidronate-treated RAW 264.7 cells. Representative proteins $(n=73)$ of each signaling pathway are plotted in a circular manner. The expressions of proliferation, some growth factors, cellular apoptosis, protection, and differentiation-related proteins were upregulated, while the expressions of protein translation-, cell survival-, angiogenesis-, and osteogenesis-related proteins were downregulated. RAS signaling and NFkB signaling were suppressed by the up-regulations of the downstream effector proteins, ERK-1 (p-ERK-1) and p38 (p-p38), respectively. The expressions of inflammatory proteins and oncogenesis-related proteins in RAW 264.7 cells were variably altered, but epigenetic methylation was increased by pamidronate treatment. Blue, yellow, and red spots indicate after 12,24 , and 48 hours of pamidronate treatment, respectively. 


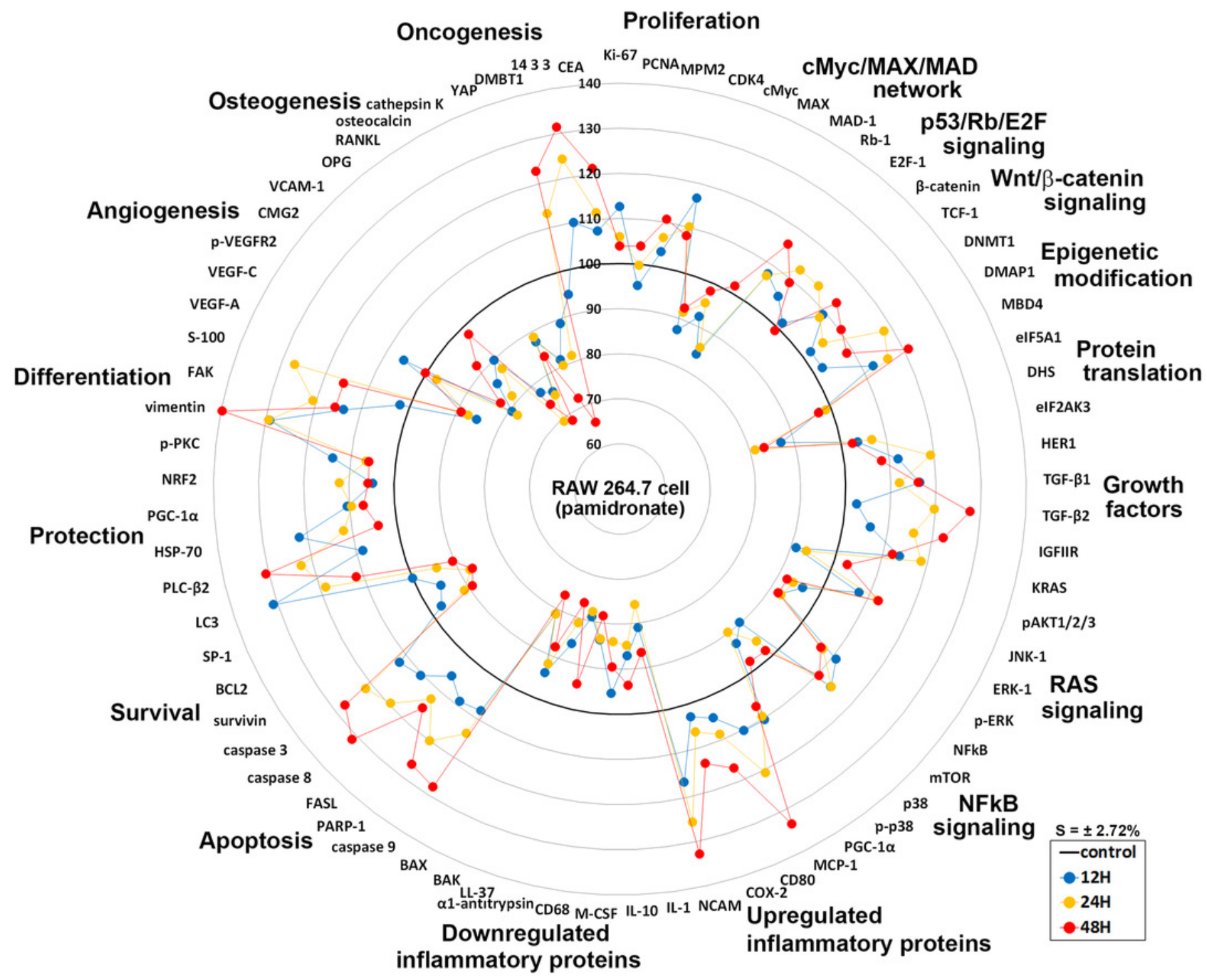




\section{Figure 9}

Highly up- and down-regulated proteins by pamidronatein RAW 264.7 cells

Figure 9. Highly up- and down-regulated proteins by pamidronate in RAW 264.7 cells. The cells were reactive to pamidronate by marked upregulation of some proteins for cellular proliferation, protection, differentiation, RAS signaling, NFkB signaling, and oncogenic proteins, but gradually degenerated by marked downregulation of M2 macrophage differentiation-related inflammatory proteins and survivalrelated proteins and by marked upregulation of apoptosis-related proteins. The major protein expressions for angiogenesis and osteoclastogenesis were dramatically suppressed (A-C). Blue, yellow, and red spots indicate after 12,24 , and 48 hours of pamidronate treatment, respectively. 

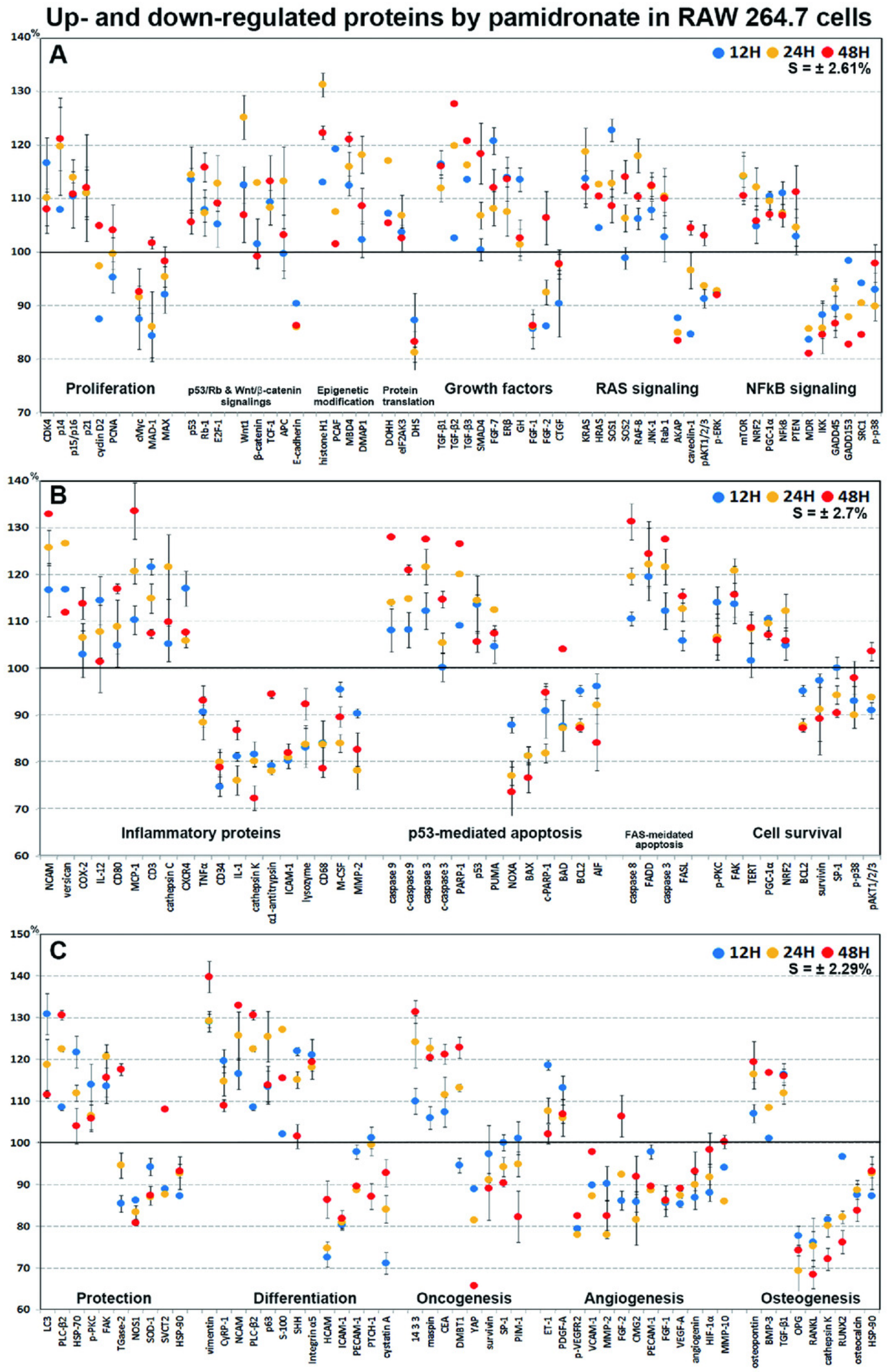


\section{Table 1 (on next page)}

Antibodies used in the study

Antibodies used in the study. 
1 Table 1. Antibodies used in the study.

\begin{tabular}{|c|c|c|}
\hline Proteins & No. & Antibodies \\
\hline Proliferation-related & 11 & Ki-67*, PCNA*, CDK4 $4^{*}, \mathrm{MPM}^{*}, \mathrm{PLK} 4^{*}$, cyclin D2, p14*, p16*, p21*, p27*, lamin A/C \\
\hline cMyc/MAX/MAD network & $3(1)$ & $\mathrm{cMyc}^{*}, \mathrm{MAX}^{*}, \mathrm{MAD}^{-1}{ }^{*},(\mathrm{p} 27)$ \\
\hline p53/Rb/E2F signaling & $4(2)$ & p53, Rb-1", E2F-1*, MDM2, (p21, CDK4) \\
\hline Wnt $/ \beta$-catenin signaling & 6 & Wnt1 ${ }^{*}, \beta$-catenin ${ }^{*}$, APC $^{*}$, snail ${ }^{*}, \mathrm{TCF}-1^{*}$, E-cadherin \\
\hline Epigenetic modification & 7 & histone $\mathrm{H} 1^{*}, \mathrm{DMAP}^{*}, \mathrm{KDM} \mathrm{D}^{\$}, \mathrm{HDAC}-10^{\$}, \mathrm{MBD}^{*}{ }^{*} \mathrm{DNMT1}^{*}, \mathrm{PCAF}^{*}$ \\
\hline Protein translation & 5 & DOHH!, DHS!, elF5A-1!, elF5A-2!, eIF2AK3* \\
\hline Growth factor & 18 & 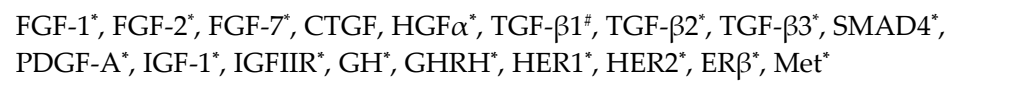 \\
\hline RAS signaling & 22 & 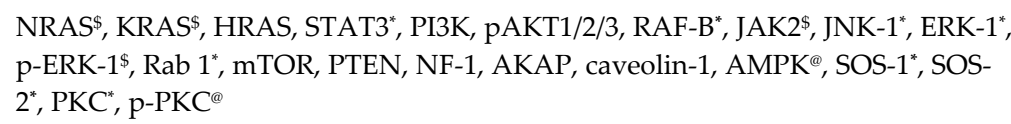 \\
\hline NFkB signaling & $12(6)$ & 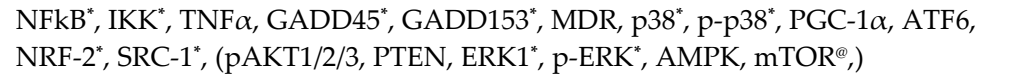 \\
\hline $\begin{array}{l}\text { Upregulated inflammatory } \\
\text { proteins }\end{array}$ & 17 & $\begin{array}{l}\text { CD3, CD4, NCAM (CD56), CD80 (B7-1), Pdcd-1/1 (CD279), IL-8, IL-12, MMP-3\$, - } \\
9^{\$},-12^{\$}, \text { CXCR4 }{ }^{*} \text {, cathepsin C, MCP-1, COX2*, lactoferrin, versican, kininogen }\end{array}$ \\
\hline $\begin{array}{l}\text { Downregulated inflammatory } \\
\text { proteins }\end{array}$ & $27(1)$ & $\begin{array}{l}\text { IL-1*, IL-6*, IL-10*, IL-28*, cathepsin G*, cathepsin K*, COX1, lysozyme*, M-CSF, } \\
\text { MMP-1, -2, -10, CD20, CD28, PECAM-1 (CD31), CD34, CD40, ICAM-1 (CD54), } \\
\text { CD68, CD99, VCAM-1 (CD106), LTA4H }{ }^{\star}, \text { LL-37, } \alpha 1 \text { - antitrypsin \&, } \beta \text {-defensin-1, } \\
\left.\beta \text {-defensin-2, } \beta \text {-defensin-3, (TNF } \alpha^{\Phi}\right)\end{array}$ \\
\hline p53-mediated apoptosis & $15(2)$ & 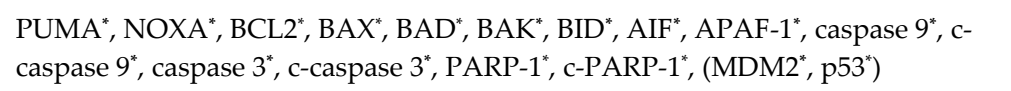 \\
\hline FAS-mediated apoptosis & $5(3)$ & FASL ${ }^{*}$, FAS $^{*}$, FADD ${ }^{*}$, FLIP ${ }^{*}$, caspase $8^{*},\left(\right.$ BID $^{*}$, caspase $3^{*}$, c-caspase $\left.3^{*}\right)$ \\
\hline Cell survival-related & $5(11)$ & $\begin{array}{l}\text { TERT }^{*} \text {, survivin }{ }^{\circledR}, \text { SP-1 }{ }^{\oplus}, \text { SP-3 }{ }^{\circledR}, \text { FAK, }(\text { pAKT1/2/3, PTEN, AMPK, BCL2, NRF2, } \\
\text { ATF6, PGC-1 } \alpha \text {, PKC, p-PKC, p38, p-p38) }\end{array}$ \\
\hline Protection-related & $12(13)$ & 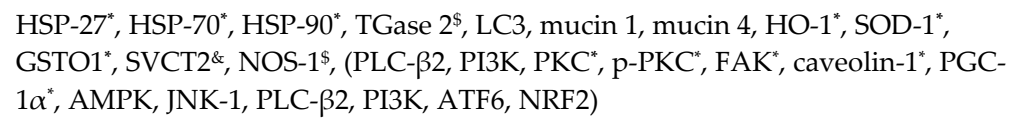 \\
\hline Differentiation-related & $11(11)$ & $\begin{array}{l}\text { p63 } 3^{\$} \text {, vimentin, } \alpha \text {-actin, PTCH-1, CyRP, SHH, cystatin A, S-100. integrin } \alpha 5 \text {, } \\
\text { HCAM (CD44), (caveolin-1, SP-1, SP-3, PLC- } 32 \text {, PI3K, PKC, p-PKC, FAK, } \\
\text { AP1M1, ICAM-1 (CD54), NCAM (CD56), PECAM (CD31)) }\end{array}$ \\
\hline Oncogenesis-related & $10(10)$ & $\begin{array}{l}\text { BRCA1\&, BRCA2\&, NF-1 }{ }^{*}, \text { ATM }^{*}, \text { CEA }^{\$}, 14-3-3^{*}, \text { maspin }^{*}, \text { DMBT1 }^{*}, \text { YAP, PIM1, } \\
\text { (MBD4, BCL2, SP-1, PTEN }{ }^{\star}, \text { mucin } 1, \text { mucin } 4 \text {, survivin }{ }^{\circledR}, \text { TERT}^{*}, \text { pAKT1/2/3*, } \\
\text { mTOR) }\end{array}$ \\
\hline Angiogenesis-related & $14(9)$ & 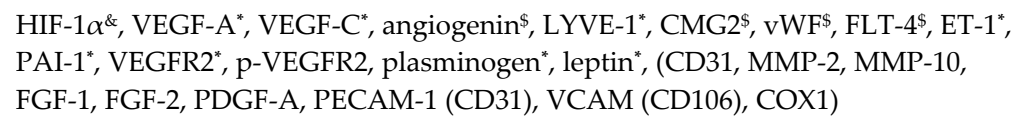 \\
\hline Osteogenesis-related & $11(4)$ & 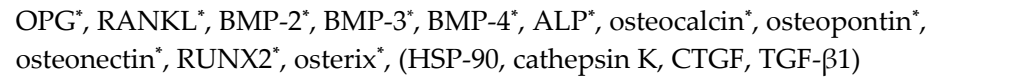 \\
\hline Control housekeeping proteins & 3 & $\alpha$-tubulin", $\beta$-actin*, GAPDH ${ }^{*}$ \\
\hline Total & $\begin{array}{l}218 \\
(73)\end{array}$ & \\
\hline
\end{tabular}

"Santa Cruz Biotechnology, USA; " DAKO, Denmark; ${ }^{\$}$ Neomarkers, CA, USA; ${ }^{\circledR}$ ZYMED, CA, USA; \&Abcam, Cambridge, UK; kindly donated from M. H. Park in NIH, USA (Park and Wolff 2018), the number of antibodies overlapped; ( ).

Abbreviations: AIF; apoptosis inducing factor, AKAP; A-kinase anchoring proteins, ALP; alkaline phosphatase, AMPK; AMPactivated protein kinase, pAKT; v-akt murine thymoma viral oncogene homolog, p-Akt1/2/3 phosphorylated (p-Akt, Thr 308), APAF-1; apoptotic protease-activating factor 1, APC; adenomatous polyposis coli, ATF6; activating transcription factor 6, ATM; ataxia telangiectasia caused by mutations, BAD; BCL2 associated death promoter, BAK; BCL2 antagonist/killer, BAX; BCL2 associated X, BCL-2; B-cell leukemia/lymphoma-2, BID; BH3 interacting-domain death agonist, BMP-2; bone morphogenesis protein 
2, BRCA1; breast cancer type 1 susceptibility protein, c-caspase 3; cleaved-caspase 3, CD3; cluster of differentiation 3, CDK4; cyclin dependent kinase 4, CEA; carcinoembryonic antigen, CMG2: capillary morphogenesis protein 2, COX-1; cyclooxygenase-2, CTGF connective tissue growth factor, CXCR4; C-X-C chemokine receptor type 4, CyRP-1; cystein rich protein, DHS; deoxyhypusine synthase, DMAP1; DNA methyltransferase 1 associated protein, DMBT1; deleted in malignant brain tumors 1, DNMT1; DNA 5cytosine methyltransferase 1, DOHH; deoxyhypusine hydroxylase, E2F-1; transcription factor, eIF2AK3 (PERK); eukaryotic translation initiation factor 2 (protein kinase R (PKR)-like endoplasmic reticulum kinase), elF5A-1; eukaryotic translation initiation factor 5A-1, ERK-1; extracellular signal-regulated protein kinase 1, ER $\beta$; estrogen receptor beta, ET-1: endothelin-1, FADD; FAS associated via death domain, FAK; focal adhesion kinase, FAS; CD95/Apo1, FASL; FAS ligand, FGF-1; fibroblast growth factor-1, FLIP; FLICE-like inhibitory protein, FLT-4; Fms-related tyrosine kinase 4, GADD45; growth arrest and DNA-damage-inducible 45, GAPDH; glyceraldehyde 3-phosphate dehydrogenase, GH; growth hormone, GHRH; growth hormone-releasing hormone, GSTO1; glutathione S-transferase $\omega$ 1, HCAM (CD44); homing cell adhesion molecule, HDAC-10; histone deacetylase 10,, HER1; human epidermal growth factor receptor 1, HGF- $\alpha$; hepatocyte growth factor $\alpha$, HIF-1 $\alpha$ : hypoxia inducible factor- $1 \alpha$, HO-1; heme oxygenase 1, HRAS; GTPase HRas, HSP-70; heat shock protein-70, ICAM (CD54); intercellular adhesion molecule 1, IGF-1; insulinlike growth factor 1, IGFIIR; insulin-like growth factor 2 receptor, IKK; ikappaB kinase, IL-1; interleukin-1, JNK-1; Jun N-terminal protein kinase, KDM4D; Lysine-specific demethylase 4D, KRAS; V-Ki-ras2 Kirsten rat sarcoma viral oncogene homolog, LC3; microtubule-associated protein 1A/1B-light chain 3, LTA4H; leukotriene A4 hydrolase, LYVE-1: lymphatic vessel endothelial hyaluronan receptor 1, MAD-1; mitotic arrest deficient 1, MAX; myc-associated factor X, MBD4; methyl-CpG-binding domain protein 4, MCP-1; monocyte chemotactic protein 1, M-CSF; macrophage colony-stimulating factor, MDM2; mouse double minute 2 homolog, MDR; multiple drug resistance, MMP-1; matrix metalloprotease-1, MPM2; mitotic protein monoclonal 2, mTOR; mammalian target of rapamycin, cMyc; V-myc myelocytomatosis viral oncogene homolog, NFkB; nuclear factor kappa-light-chainenhancer of activated B cells, NCAM (CD56); neural cell adhesion molecule 1, NF-1; neurofibromin 1, NFkB; nuclear factor kappalight-chain-enhancer of activated B cells, NOS-1; nitric oxide synthase 1, NOXA; Phorbol-12-myristate-13-acetate-induced protein 1, NRAS; neuroblastoma RAS Viral Oncogene homolog, NRF2; nuclear factor (erythroid-derived)-like 2, OPG; osteoprotegerin, PAI1; plasminogen activator inhibitor-1, PARP-1; poly-ADP ribose polymerase 1, c-PARP-1; cleaved-PARP-1, PCNA; proliferating cell nuclear antigen, Pdcd-1/1 (CD279); programmed cell death protein 1, PDGF-A: platelet-derived growth factor-A, PECAM-1 (CD31); platelet endothelial cell adhesion molecule-1, PGC-1 $\alpha$; peroxisome proliferator-activated receptor gamma coactivator $1-\alpha$, PI3K; phosphatidylinositol-3-kinase, PIM-1; Proto-oncogene serine/threonine-protein kinase 1, PKC; protein kinase C, PLC- $\beta 2$; 1 phosphatidylinositol-4,5-bisphosphate phosphodiesterse $\beta$-2, PLK4; polo like kinase 4 or serine/threonine-protein kinase, PTEN; phosphatase and tensin homolog, PUMA; p53 upregulated modulator of apoptosis, Rab 1; Rab GTPases, RAF-B; v-Raf murine sarcoma viral oncogene homolog B, RANKL; receptor activator of nuclear factor kappa-B ligand, Rb-1; retinoblastoma-1, RUNX2; Runt-related transcription factor-2, SHH; sonic hedgehog, SMAD4; mothers against decapentaplegic, drosophila homolog 4, SOD1; superoxide dismutase-1, SOS-1; son of sevenless homolog 1, SP-1; specificity protein 1, SRC1; steroid receptor coactivator-1, STAT3; signal transducer and activator of transcription-3, SVCT2; sodium-dependent vitamin C transporter 2, TERT; human telomerase reverse transcriptase, TGase-2; transglutaminase 2 , TGF- $\beta 1$; transforming growth factor- $\beta 1$, TNF $\alpha$; tumor necrosis factor$\alpha$, VCAM; vascular cell adhesion molecule-1, VEGF-A vascular endothelial growth factor A, VEGFR2: vascular endothelial growth factor receptor 2, p-VEGFR2: vascular endothelial growth factor receptor 2 (Y951), vWF: von Willebrand factor, Wnt1; protooncogene protein Wnt-1, YAP; Yes-associated protein. 